\title{
Expedient Synthesis and Design Strategies for New Peptoid Construction
}

\author{
Benjamin C. Gorske, Sarah A. Jewell, Emily J. Guerard, and Helen E. Blackwell* \\ Department of Chemistry, University of Wisconsin - Madison, \\ 1101 University Ave., Madison, WI 53706-1322 \\ e-mail: blackwell@chem.wisc.edu
}

\section{Supporting Information.}

General experimental information......................................... S-2

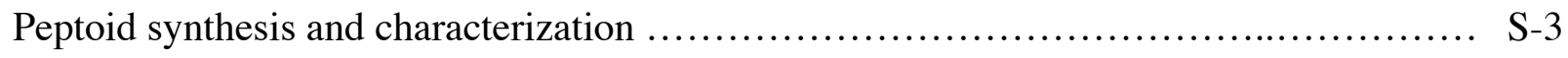

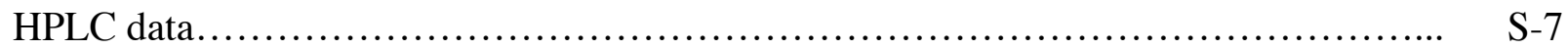

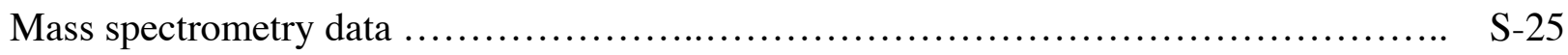

* To whom correspondence should be addressed. 
General. Analytical reverse-phase HPLC was performed using either a Beckman Coulter (System Gold 126P solvent module, System Gold 168 UV Detector, System Gold 508 autosampler) or a Shimadzu (SCL-10Avp controller, LC-6AD pumps, SPD-10Avp UV/vis detector) system. Mobile phase $\mathrm{A}=0.1 \%$ TFA in water; mobile phase $\mathrm{B}=0.1 \%$ TFA in acetonitrile. Purities were determined by integration at $220 \mathrm{~nm}$. A C8 column (Zorbax Rx-C8, $4.6 \mathrm{~mm} \times 25 \mathrm{~cm}$ ) was used for analysis of all peptoid homo-pentamers, and a C4 column (Vydac, $4.6 \mathrm{~mm} \times 25 \mathrm{~cm}$ ) was used for analysis of all peptoid nonamers. Preparative reverse-phase HPLC was performed using a Shimadzu (SCL-10Avp controller, LC-6AD pumps, SPD-10Avp $\mathrm{UV} / \mathrm{vis}$ detector) system. A Vydac C4-silica preparative column $(10 \mu \mathrm{m}, 22 \mathrm{~mm}$ x $250 \mathrm{~mm})$ was used for all preparative work.

LC-MS were obtained using a Shimadzu LCMS-2010 equipped with two pumps (LC10ADvp), controller (SCL-10Avp), autoinjector (SIL-10ADvp), UV diode array detector (SPDM10Avp), and single quadrupole analyzer (by electrospray ionization (ESI)). A Supelco $15 \mathrm{~cm}$ $\times 2.1 \mathrm{~mm} \mathrm{C18}$ wide-pore reverse phase column was used for all LC-MS work. Standard reverse phase LC conditions were as follows: flow rate $=200 \mu \mathrm{L} / \mathrm{min}$; mobile phase $\mathrm{A}=0.4 \%$ formic acid; mobile phase $\mathrm{B}=0.2 \%$ formic acid in acetonitrile.

ESI mass spectra were obtained with a Waters/Micromass LCT. This instrument has a magnetic sector; samples are placed in a piece of glass capillary and inserted directly into the source, and the resulting vapor is bombarded with $70 \mathrm{eV}$ electrons. Perfluorokerosene (PFK) was used for calibration. The matrix-assisted laser desorption/ionization (MALDI) mass spectra were obtained using a Bruker REFLEX II equipped with a $337 \mathrm{~nm}$ laser, a reflectron, and delayed extraction. In positive ion mode, the acceleration voltage was $25 \mathrm{kV}$.

Circular dichroism (CD) spectra were obtained on either a Jasco J-715 spectropolarimeter with J-700 for Windows Standard Analysis (v. 1.50.01) software or an Aviv 62A DS spectropolarimeter with Aviv CDS software. Data were analyzed and plotted using IGOR Professional and Microsoft Excel 2004.

All reagents were purchased from commercial sources (Alfa-Aesar, Aldrich, Advanced ChemTech, and Acros) and used without further purification. Solvents were purchased from commercial sources (Aldrich and J. T. Baker) and used as is, with the exception of dichloromethane $\left(\mathrm{CH}_{2} \mathrm{Cl}_{2}\right)$, which was distilled over calcium hydride immediately prior to use. Fmoc-protected Rink amide resin (100-200 mesh, Advanced ChemTech) was used for all solidphase syntheses.

Microwave instrumentation. All microwave reactions were carried out in a Milestone MicroSYNTH Labstation multimodal microwave synthesis reactor equipped with a continuous power source (1000 W max). This instrument is interfaced with an Ethos MicroSYNTH Lab Terminal PC running EasyWave reaction monitoring software. Using this reactor system, microwave irradiation can be applied to reactions using either wattage (power) control or temperature control. The microwave reactor is equipped with a fiber-optic temperature sensor that allows direct monitoring of the internal temperature of reaction vessels, and an infrared sensor (installed in the side wall of the reactor cavity) that monitors the surface temperature of any reaction vessel inside the cavity. Solid-phase reactions were performed in the MicroSYNTH 


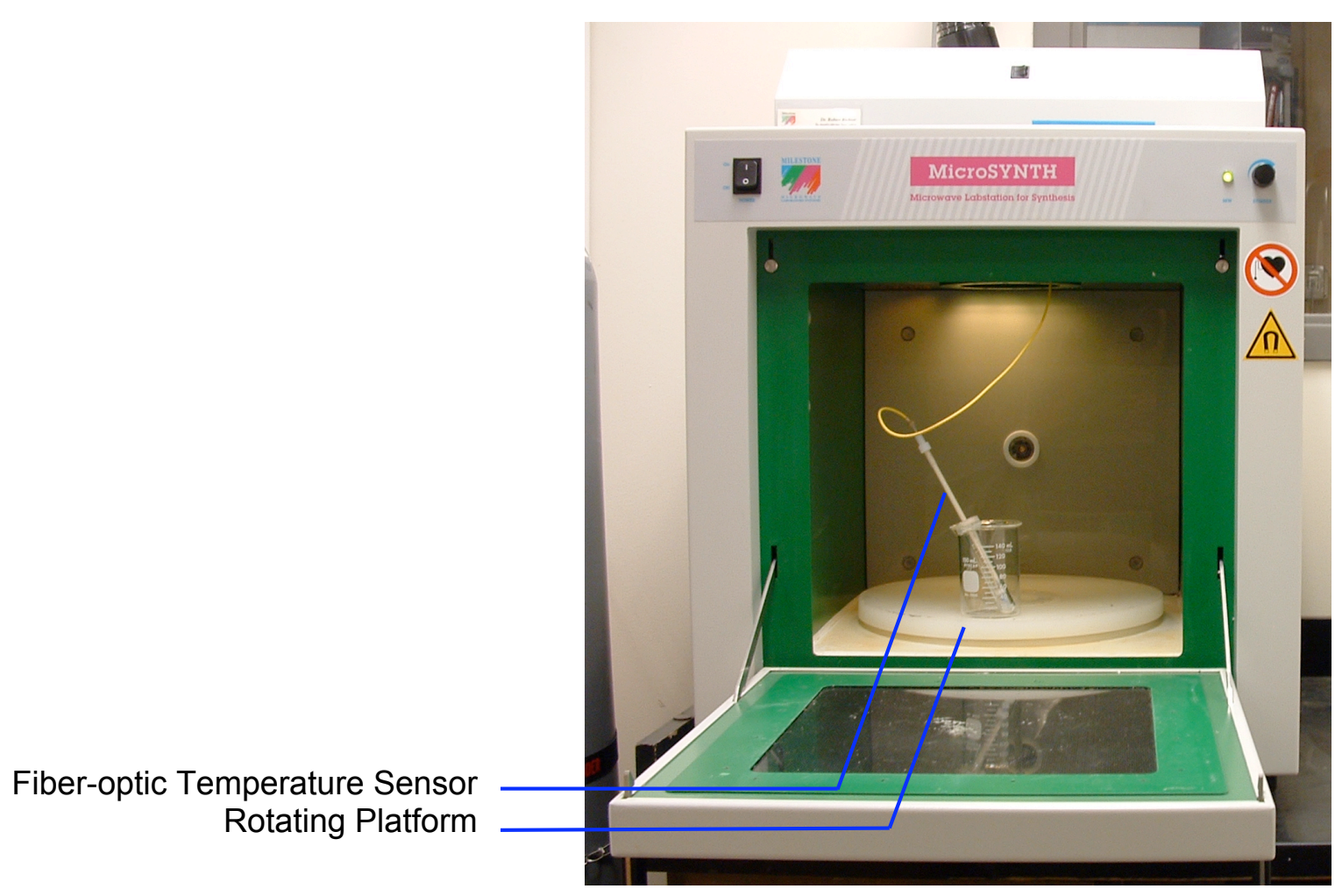

Figure S-1. Microwave instrumentation used for solidphase peptoid synthesis.

reactor on a rotating turntable inside the MicroSYNTH microwave reactor (Figure S-1). A builtin stirrer was used to agitate the resin during reactions.

\section{Peptoid Synthesis and Characterization}

All solid-phase reactions carried out in the microwave were performed in the apparatus shown in Figure S-2. The resin and a micro stir bar were placed in a Bohdan 4-mL solid-phase synthesis vessel (\#MTB2001). The male luer outlet was fitted with a cap (Alltech, \#220710), and the vessel was placed in a CEM reaction vial (\#908035). A CEM non-invasive vial cap (\#SP1318A) was punctured with pliers and used to cap the reaction vial. The sheath for the Milestone fiber-optic temperature probe was then threaded through the puncture in the vial cap. The fiber-optic probe was inserted into the sheath, and the entire assembly was placed in a beaker for support, as shown in Figure S-1. The beaker was placed on a rotating platform, the stirrer was set to its maximum setting, and the reaction mixture was heated utilizing temperature control.

Optimized Microwave Synthesis Protocol. Approximately $75 \mathrm{mg}$ of $0.75 \mathrm{mmol} / \mathrm{g}$ Fmocprotected Rink amide resin (100-200 mesh) were weighed in a Bohdan 4-mL solid-phase synthesis vessel and deprotected with 20\% piperidine/DMF (1 x 1 min, 1 x 15 min), then washed with DMF (6 x $5 \mathrm{sec}, 1 \times 2 \mathrm{~min})$. The apparatus for microwave heating was assembled as described above. $2.0 \mathrm{M}$ bromoacetic acid (99\%) in dry DMF (1 mL) and $2.0 \mathrm{M} \mathrm{N,N^{ \prime } -}$ 
diisopropylcarbodiimide (DIC) in dry DMF $(1 \mathrm{~mL})$ were added, and the acylation reaction was performed in a Milestone Microsynth reactor (30 sec ramp to $35^{\circ} \mathrm{C}$ using temperature control). The luer cap was removed, and the reagents were immediately drained. The resin was washed with DMF (6 x $5 \mathrm{sec}, 1 \times 2 \mathrm{~min})$. A $1.0 \mathrm{M}$ amine solution in dry DMF ( $2 \mathrm{~mL})$ was added and the vessel was again placed in the apparatus shown. The amination reaction was performed in a Milestone Microsynth (90 sec ramp to $95{ }^{\circ} \mathrm{C}$ using temperature control). The reagents were immediately drained and the resin was washed with $\mathrm{DMF}(6 \times 5 \mathrm{sec}, 1 \times 2 \mathrm{~min})$. The resin was then subjected to these two reaction conditions iteratively to construct the desired peptoid. At the end of the synthesis, the beads were washed with DMF $(7 \times 5 \mathrm{sec})$ and methylene chloride (4 $\mathrm{x} 2 \mathrm{~min}$ ).

$25{ }^{\circ} \mathrm{C}$ Control for the Optimized Microwave Synthesis Protocol. The syntheses were performed exactly as described for the Optimized Microwave Synthesis protocol above, except that the reactions were performed while stirring on a stir plate at room temperature.

Domestic Microwave Synthesis Protocol in the Milestone System. ${ }^{1}$ Approximately 75 $\mathrm{mg}$ of $0.75 \mathrm{mmol} / \mathrm{g}$ Fmoc-protected Rink amide resin (100-200 mesh) were weighed in a Bohdan 4-mL solid-phase synthesis vessel and swelled in DMF for $30 \mathrm{~min}$. The resin was deprotected with $20 \%$ piperidine/DMF ( 2 x $20 \mathrm{~min})$, then washed with DMF (8 x $2.5 \mathrm{~mL}, 2 \mathrm{~min}$ each). 2.0 M bromoacetic acid (99\%) in dry DMF (1 mL) and 2.0 M DIC in dry DMF (1 mL) were added, and the vessel was placed in the apparatus shown in Figure S-2, but without the temperature probe and stir bar. The mixture was shaken manually for $30 \mathrm{sec}$. The apparatus was then placed on the rotating platform in the Milestone microwave reactor and heated at $10 \%$ power $(100 \mathrm{~W})$ for $15 \mathrm{sec}$. The beads were shaken manually for $15 \mathrm{sec}$, and then heated again at $10 \%$ power $(100 \mathrm{~W})$ for $15 \mathrm{sec}$. The resin was washed with DMF (8 x $4 \mathrm{~mL}, 2$ min each) and anhydrous DMF ( $2 \times 2 \mathrm{~mL}, 2 \mathrm{~min}$ each). A $1.0 \mathrm{M}$ amine solution in dry DMF (2 mL) was added and the mixture was shaken manually for $15 \mathrm{sec}$. The apparatus was then placed on the rotating platform in the Milestone microwave reactor and heated at $10 \%$ power $(100 \mathrm{~W})$ for $15 \mathrm{sec}$. The beads were shaken manually for $15 \mathrm{sec}$, and then heated again at $10 \%$ power $(100 \mathrm{~W})$ for $15 \mathrm{sec}$. The resin was washed with DMF ( $8 \times 4 \mathrm{~mL}, 2 \mathrm{~min}$ each) and anhydrous DMF $(2 \times 2 \mathrm{~mL}, 2 \mathrm{~min}$ each). At the end of the synthesis, the beads were washed with methylene chloride $(8 \times 2.5 \mathrm{~mL}$, 2 min each) and dried under nitrogen.

Standard Synthesis Protocol. ${ }^{1} \quad$ Approximately $75 \mathrm{mg}$ of $0.75 \mathrm{mmol} / \mathrm{g}$ Fmoc-protected Rink amide resin (100-200 mesh) were weighed in a Bohdan 4-mL solid-phase synthesis vessel and swelled in DMF for $30 \mathrm{~min}$. The resin was deprotected with $20 \%$ piperidine/DMF $(2 \times 20$ $\mathrm{min})$, then washed with DMF (6 x $5 \mathrm{sec}, 1 \times 2 \mathrm{~min})$. A luer cap was fitted to the vessel. $2.0 \mathrm{M}$ bromoacetic acid (99\%) in dry DMF (1 mL) and 2.0 M DIC in dry DMF (1 mL) were added, and the vessel was placed in the apparatus shown in Figure S-2, but without the temperature probe. A stir bar was added, and the mixture was stirred for 30 minutes at room temperature. The reaction mixture was filtered and resubjected to the acylation conditions. The resin was then washed with DMF (6 x $5 \mathrm{~s}, 1 \times 2 \mathrm{~min})$. A $1.0 \mathrm{M}$ amine solution in dry DMF ( $2 \mathrm{~mL})$ was added and stirred for $2 \mathrm{hr}$. The resin was washed with DMF ( 6 × $5 \mathrm{sec}, 1 \times 2 \mathrm{~min})$, and then subjected to

(1) Olivos, H. J.; Alluri, P. G.; Reddy, M. M.; Salony, D.; Kodadek, T. Org. Lett. 2002, 4, 4057-4059. 
the addition of the next residue. At the end of the synthesis, the beads were washed with DMF ( 7 x $5 \mathrm{sec}$ ) and methylene chloride (4 $\times 2$ min) and dried under nitrogen.

Peptoid Cleavage Protocols. The resin was cleaved with $1 \mathrm{~mL}$ of $95 \%$ trifluoroacetic acid $/ 5 \% \mathrm{H}_{2} \mathrm{O}$ for $2 \mathrm{hr}$. Peptoids containing amines that rendered them acid-sensitive (5, 6, and 19) were cleaved from the resin for $20 \mathrm{~min}$. The resin was then rinsed with $\mathrm{CH}_{2} \mathrm{Cl}_{2}(2 \times 2 \mathrm{~mL})$. The solution was evaporated under a stream of nitrogen until a waxy solid was obtained, which was then stored at $-5^{\circ} \mathrm{C}$.

Purity Analyses. The samples were analyzed by HPLC, and purities were determined by integration at $220 \mathrm{~nm}$. A C8 column (Zorbax Rx-C8, $4.6 \mathrm{~mm}$ x $25 \mathrm{~cm}$ ) was used for analysis of all peptoid homo-pentamers. A C4 column (Vydac, $4.6 \mathrm{~mm}$ x $25 \mathrm{~cm}$ ) was used for analysis of all peptoid nonamers. The gradient elution was $10-90 \%$ solvent B in 50 minutes. Fractions containing the desired products were collected and analyzed by ESI or MALDI-TOF mass spectral analysis.

Peptoid Purification. Peptoid nonamers (20-22) were purified to $>95 \%$ homogeneity by preparative reverse-phase HPLC. Gradient elution was 51-64\% solvent B in 26 minutes for 20, $56-71 \%$ solvent B in 30 minutes for $\mathbf{2 1}$, and $56-71 \%$ solvent B in 30 minutes for $\mathbf{2 2}$. The solvent was removed in vacuo using a SpeedVac at $40{ }^{\circ} \mathrm{C}$ (Thermosavant SC250 Express with OFP-400 vacuum pump and RVT4104 refrigerated vapor trap) for $\mathbf{2 1}$ and 22. HPLC fractions of $\mathbf{2 0}$ were subjected to lyophilization (VirTis bench top lyophilizer). All three nonamer peptoids (20-22) were isolated as white powders.

CD Analyses. CD spectra were obtained in a square quartz cell (path length $0.2 \mathrm{~cm}$ on Jasco; $0.1 \mathrm{~cm}$ on Aviv) at room temperature using a scan rate of $100 \mathrm{~nm} / \mathrm{min}$, with five averaged scans per spectrum. Peptoid stock solutions were made immediately prior to $\mathrm{CD}$ analysis by dissolving ca. $2 \mathrm{mg}$ of peptoid in $5 \mathrm{~mL}$ of spectroscopic grade acetonitrile. The stock solutions were diluted to the desired concentration (approximately $60 \mu \mathrm{M})^{2}$ using a $1000 \mu \mathrm{L}$ calibrated micropipette.

(2) Wu, C. W.; Sanborn, T. J.; Zuckermann, R. N.; Barron, A. E. J. Am. Chem. Soc. 2001, 123, 29582963. 


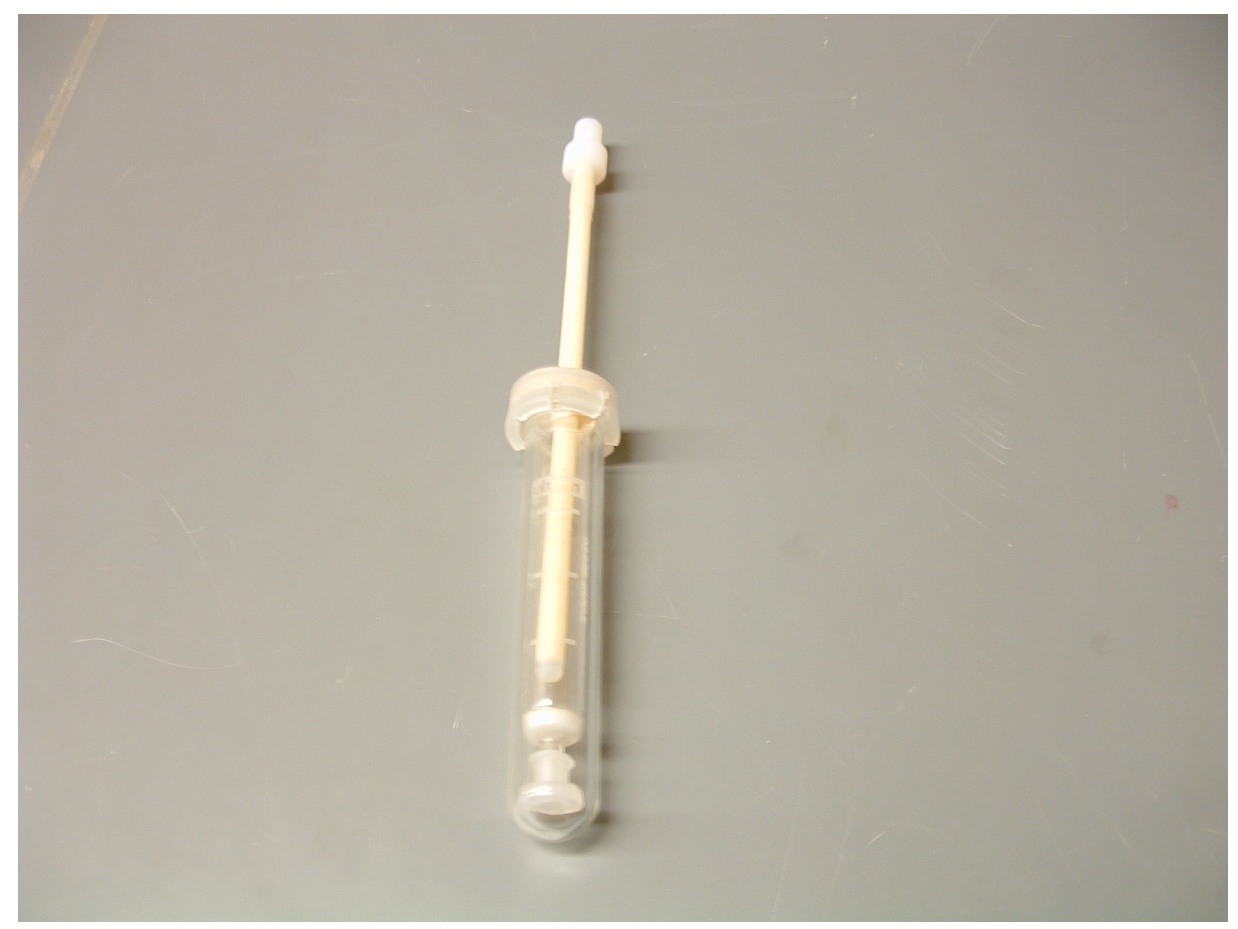

Figure S-2. Apparatus for microwave-assisted solid-phase peptoid synthesis.

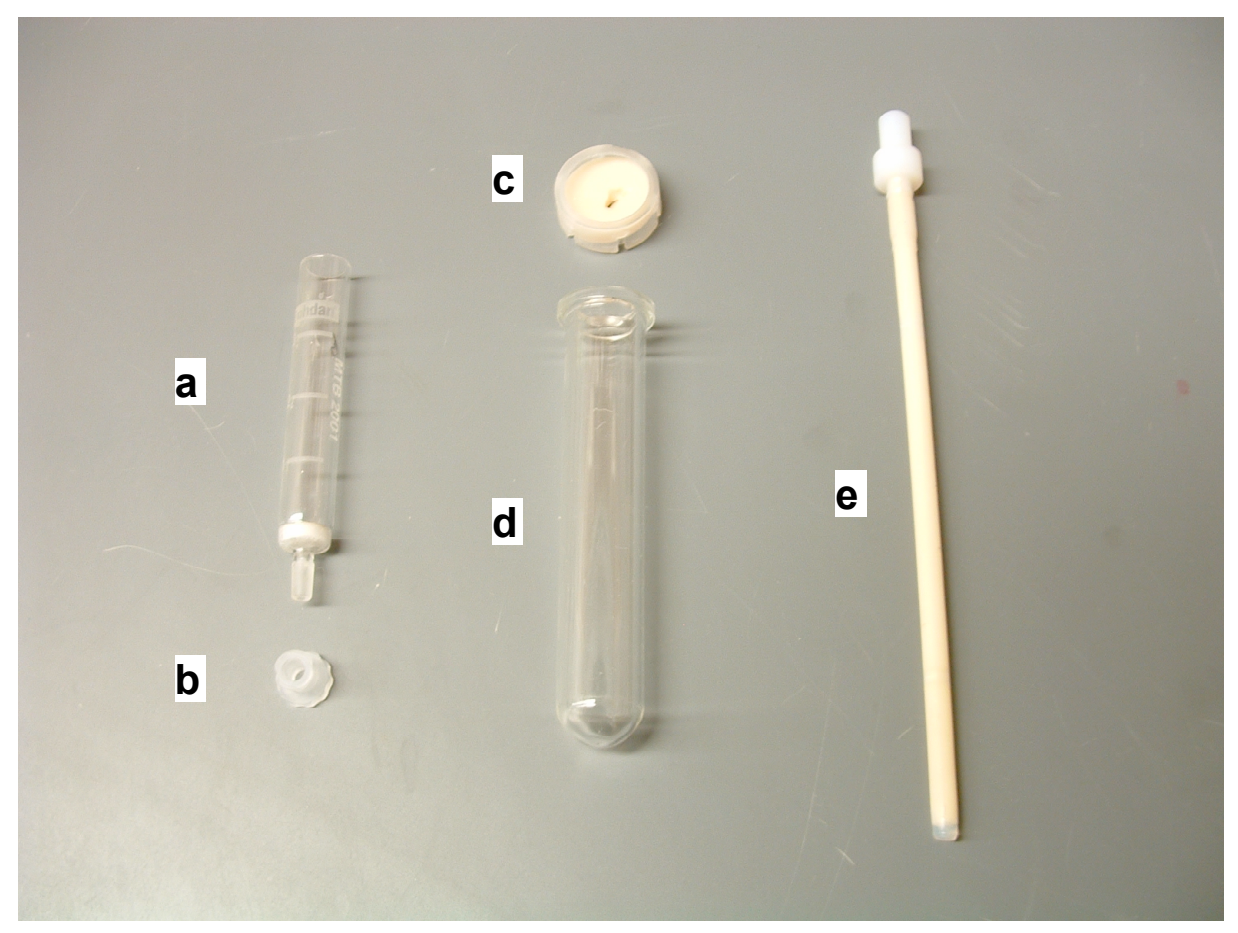

Figure S-3. Equipment for assembly of the apparatus in Figure S-2. a) Bohdan 4-mL solid-phase synthesis vessel (\#MTB2001). b) luer cap (Alltech, \#220710). c) CEM non-invasive vial cap (\#SP1318A). d) CEM reaction vial (\#908035). e) sheath for Milestone fiber-optic temperature probe. 


\section{HPLC data}

"MW Conditions" - See the Optimized Microwave Synthesis Protocol above.

" $25^{\circ} \mathrm{C}$ control" - See the $25^{\circ} \mathrm{C}$ Control for the Optimized Microwave Synthesis Protocol above.

5: $(N \text { spe })_{5}, \mathrm{MW}$ Conditions

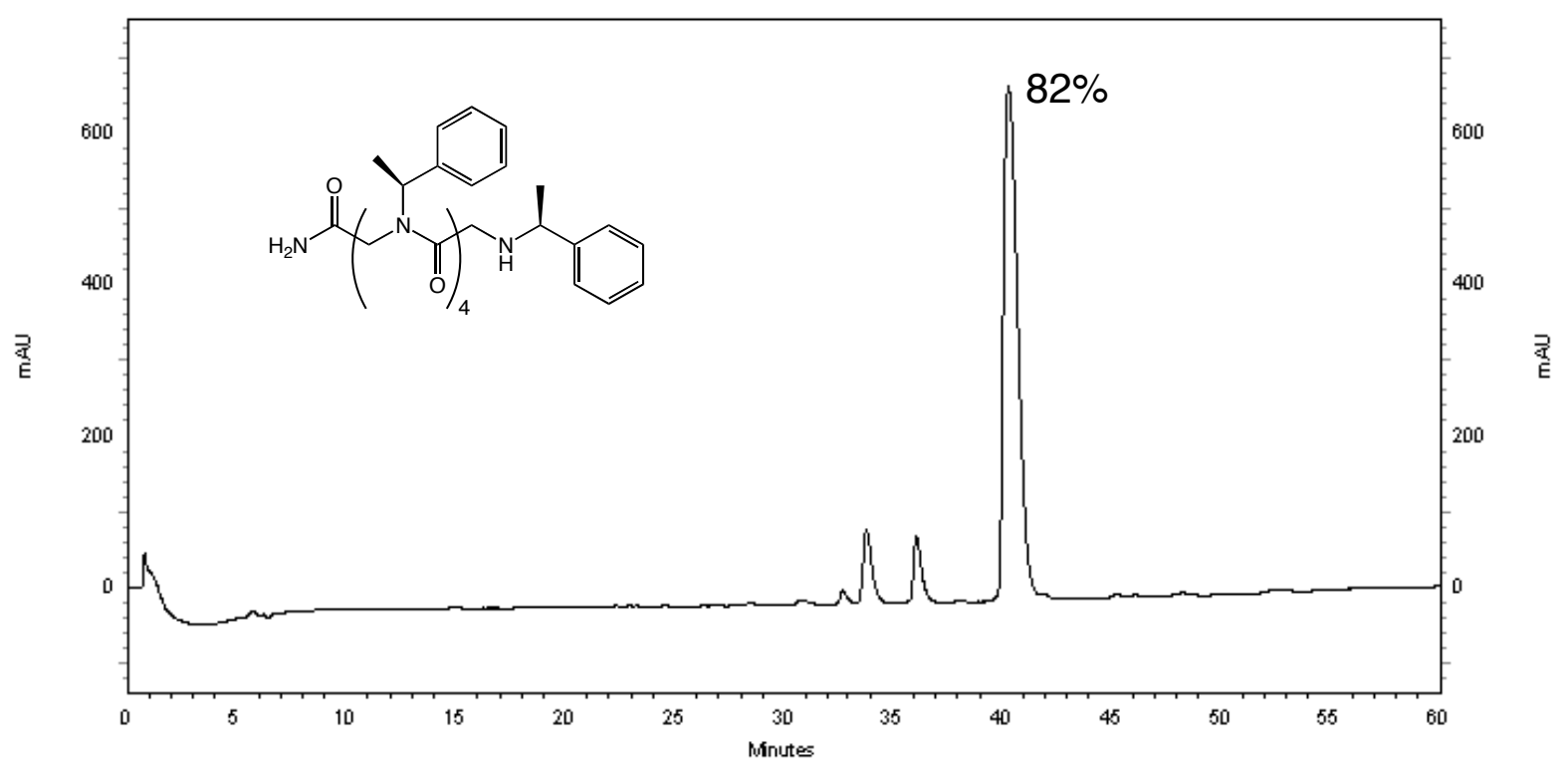

5: $(\text { Nspe })_{5}, 25^{\circ} \mathrm{C}$ control

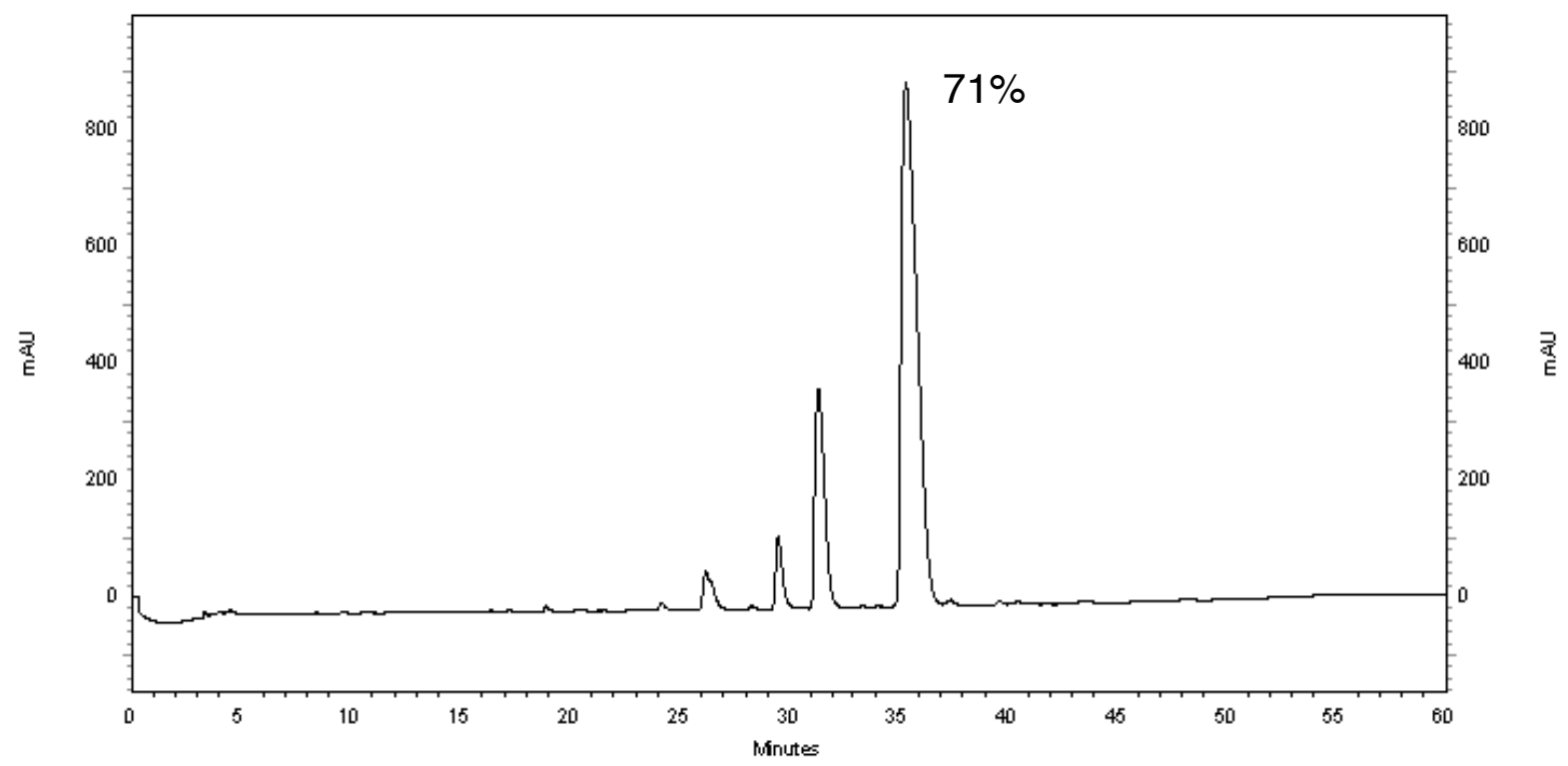


Gorske et al.

6: $(N \mathrm{sch})_{5}, \mathrm{MW}$ Conditions

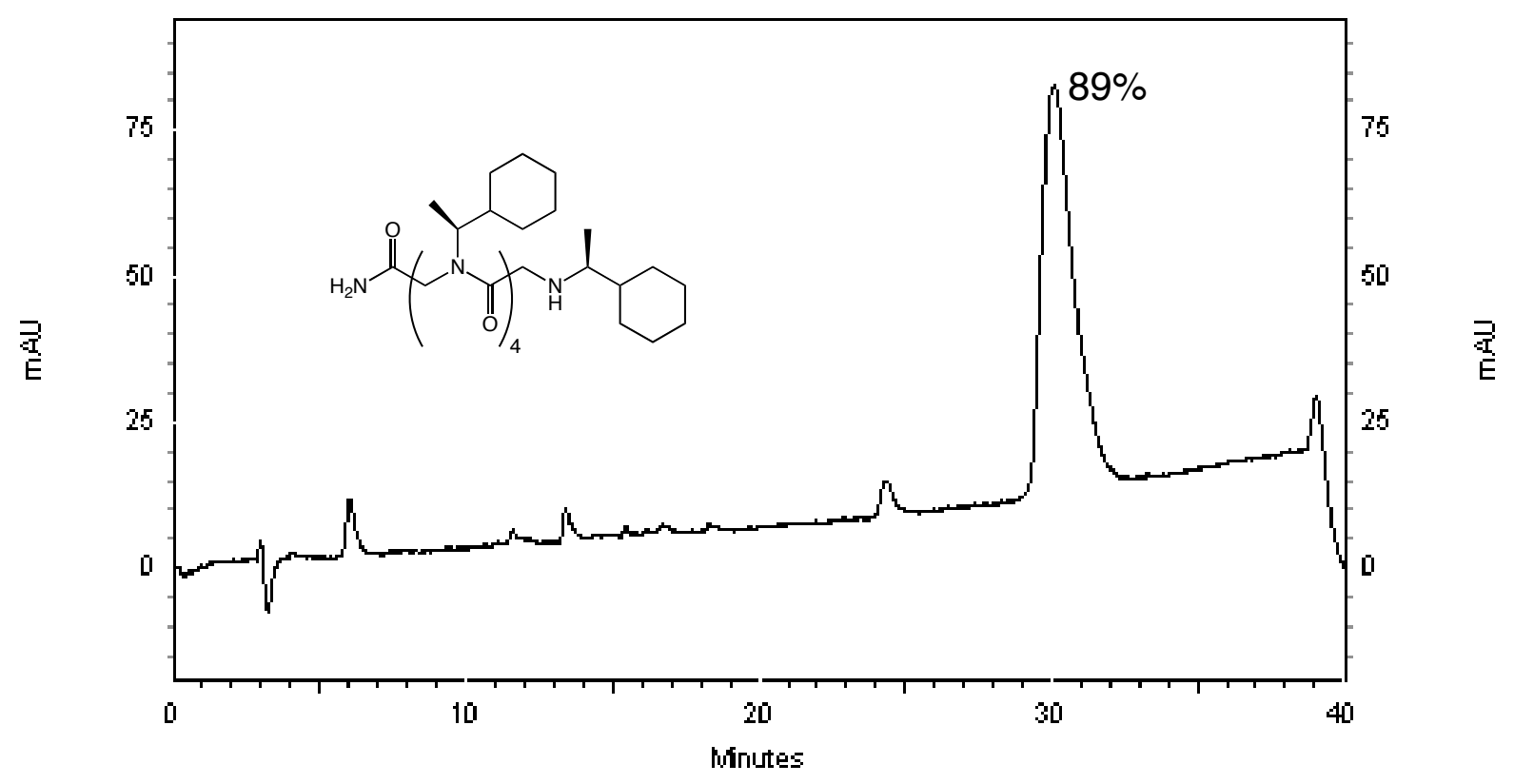

6: $(N \mathrm{sch})_{5}, 25^{\circ} \mathrm{C}$ control

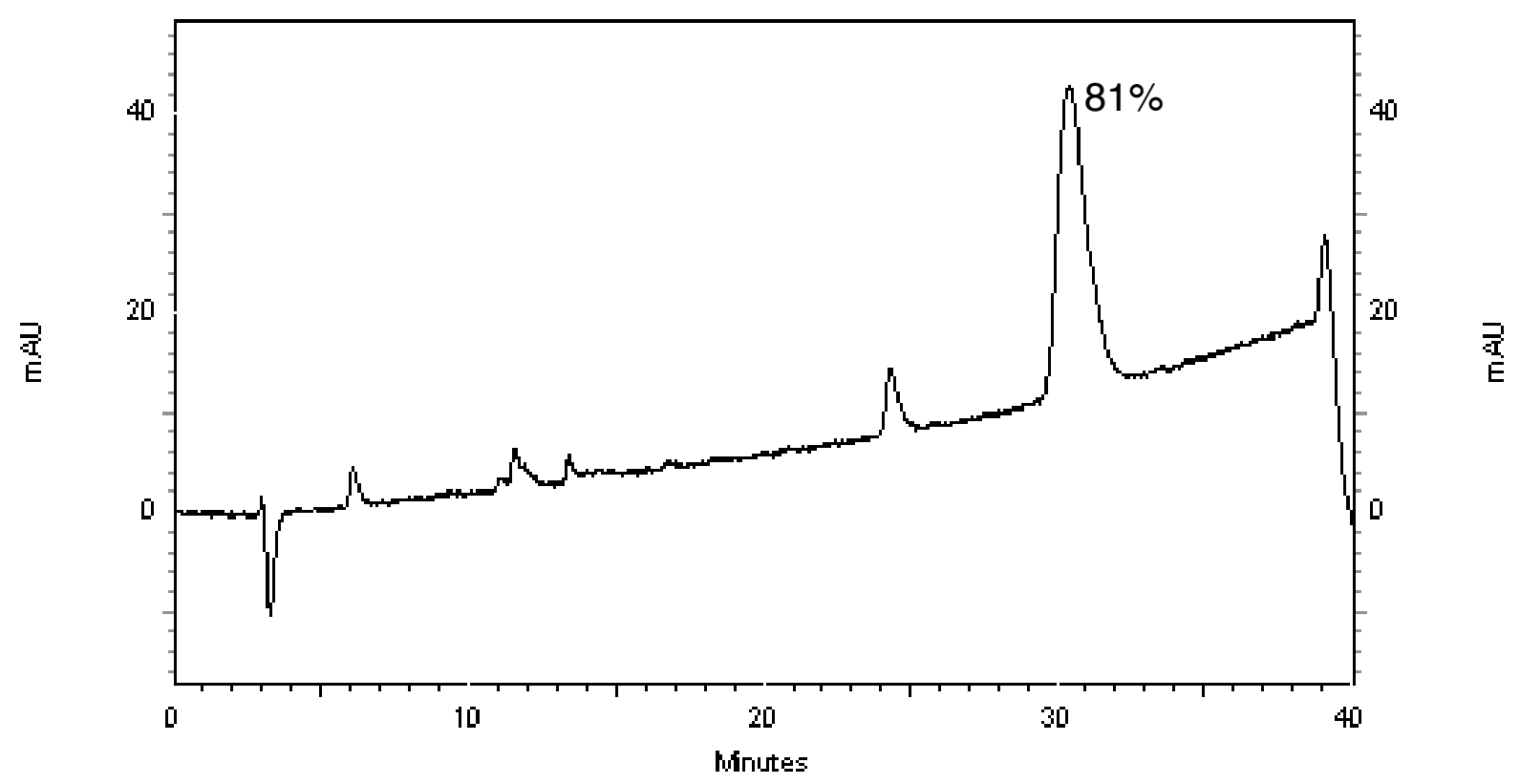


Gorske et al.

7: $(\mathrm{Npm})_{5}, \mathrm{MW}$ Conditions

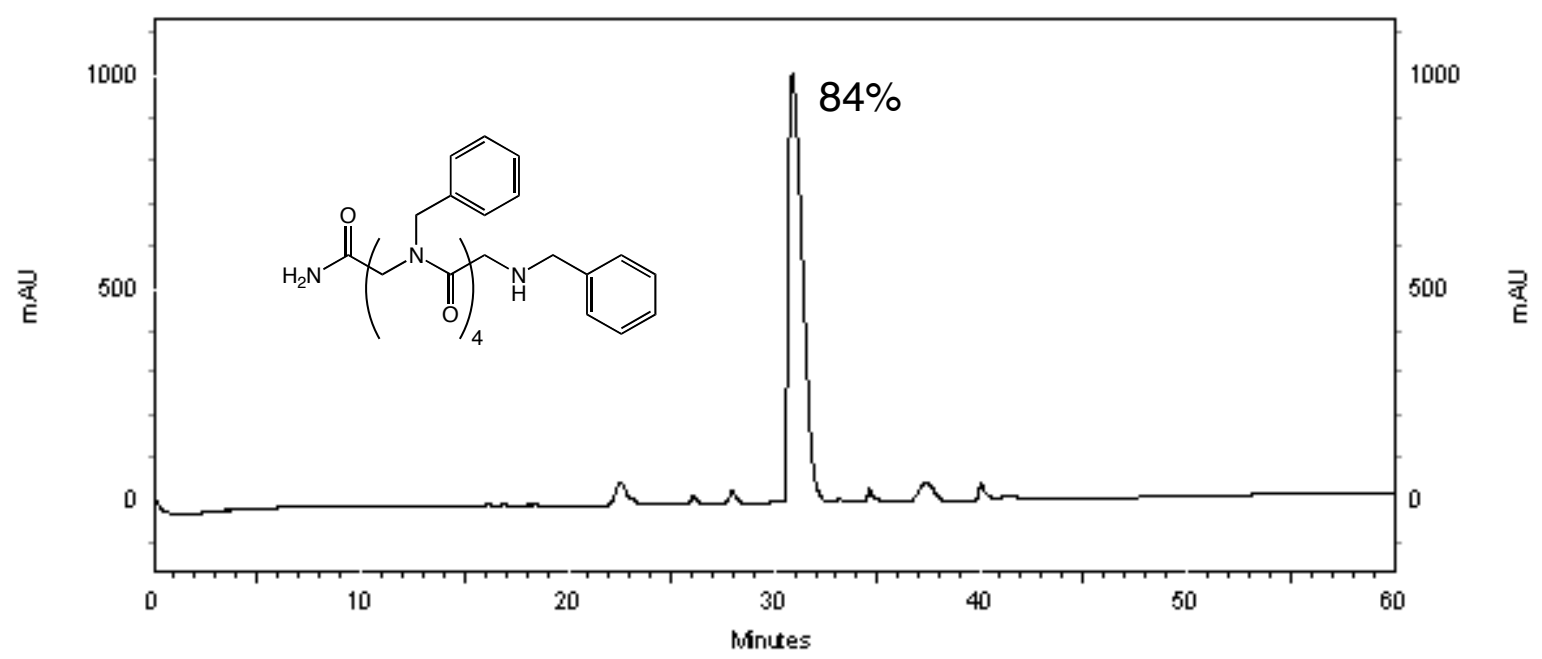

7: $(N \mathrm{pm})_{5}, 25{ }^{\circ} \mathrm{C}$ control

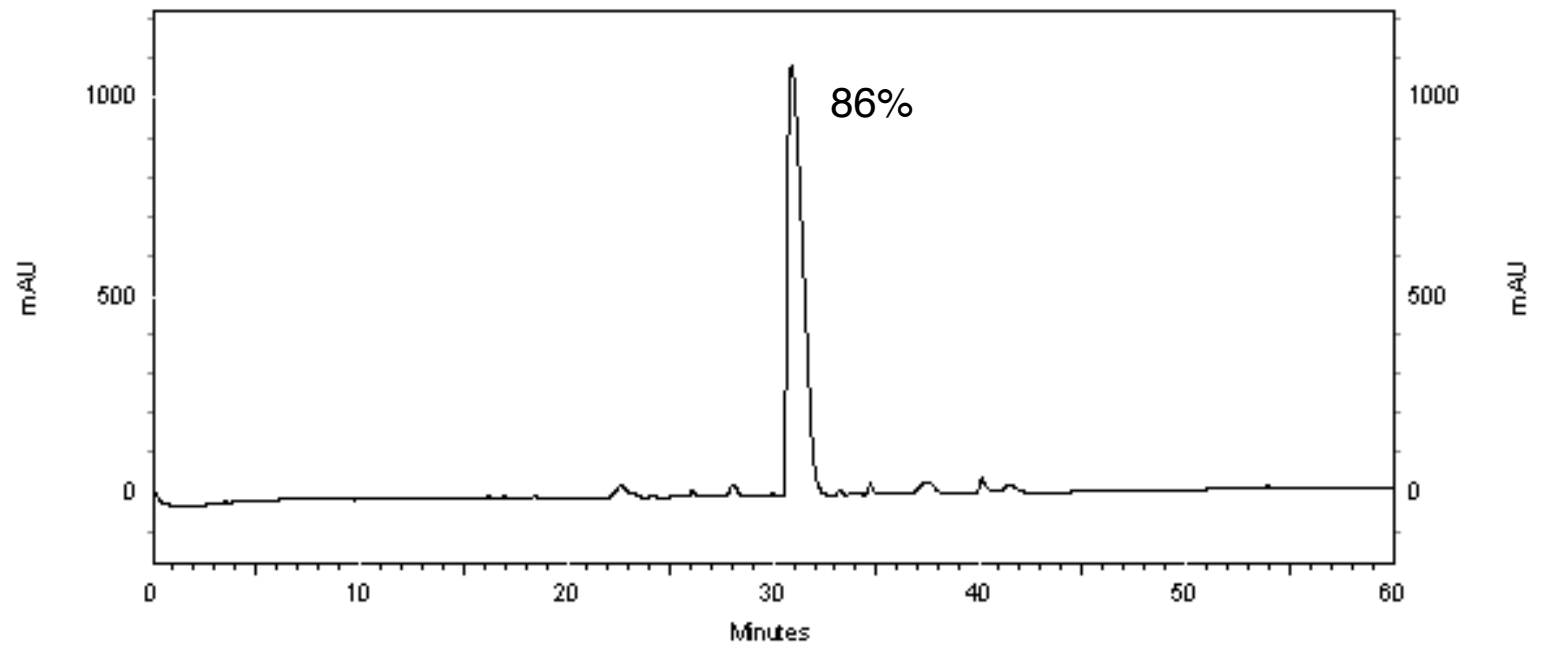


Gorske et al.

8: $(N \mathrm{spp})_{5}$, MW Conditions

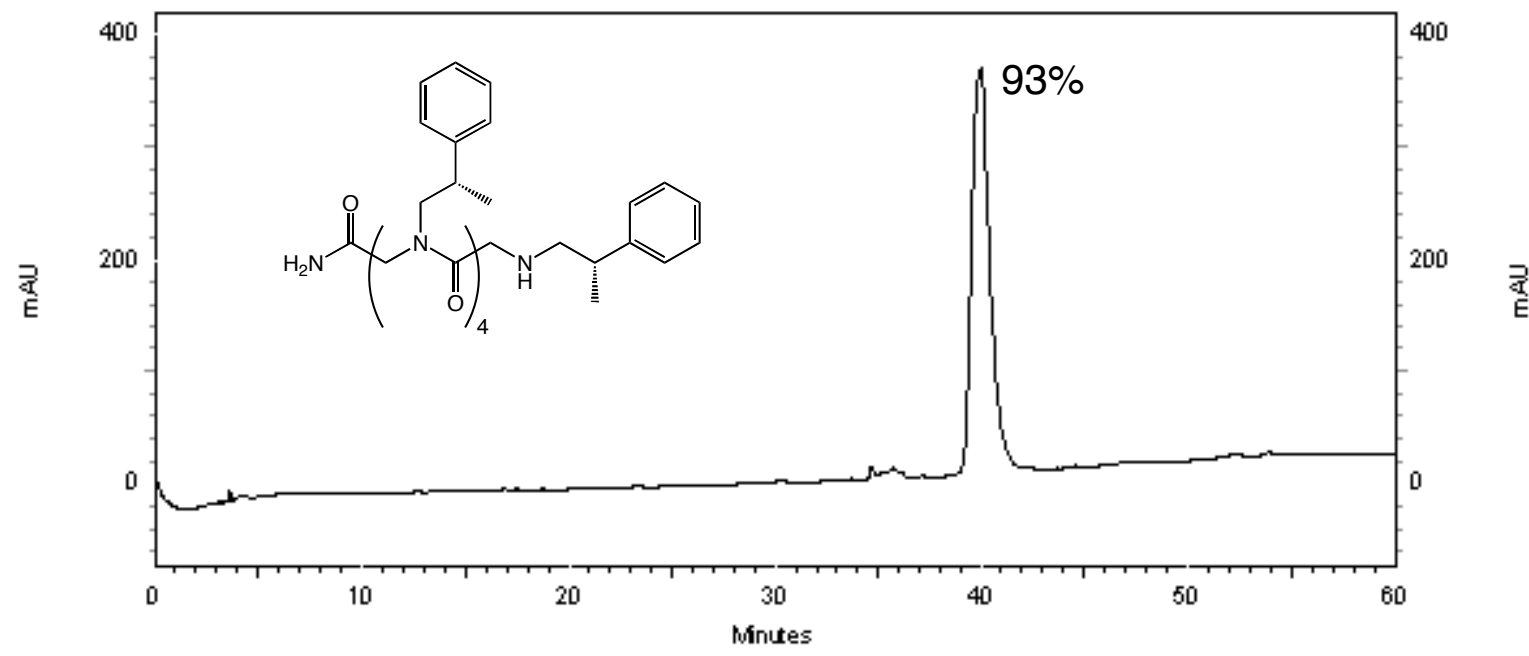

8: $(N \text { spp })_{5}, 25{ }^{\circ} \mathrm{C}$ control

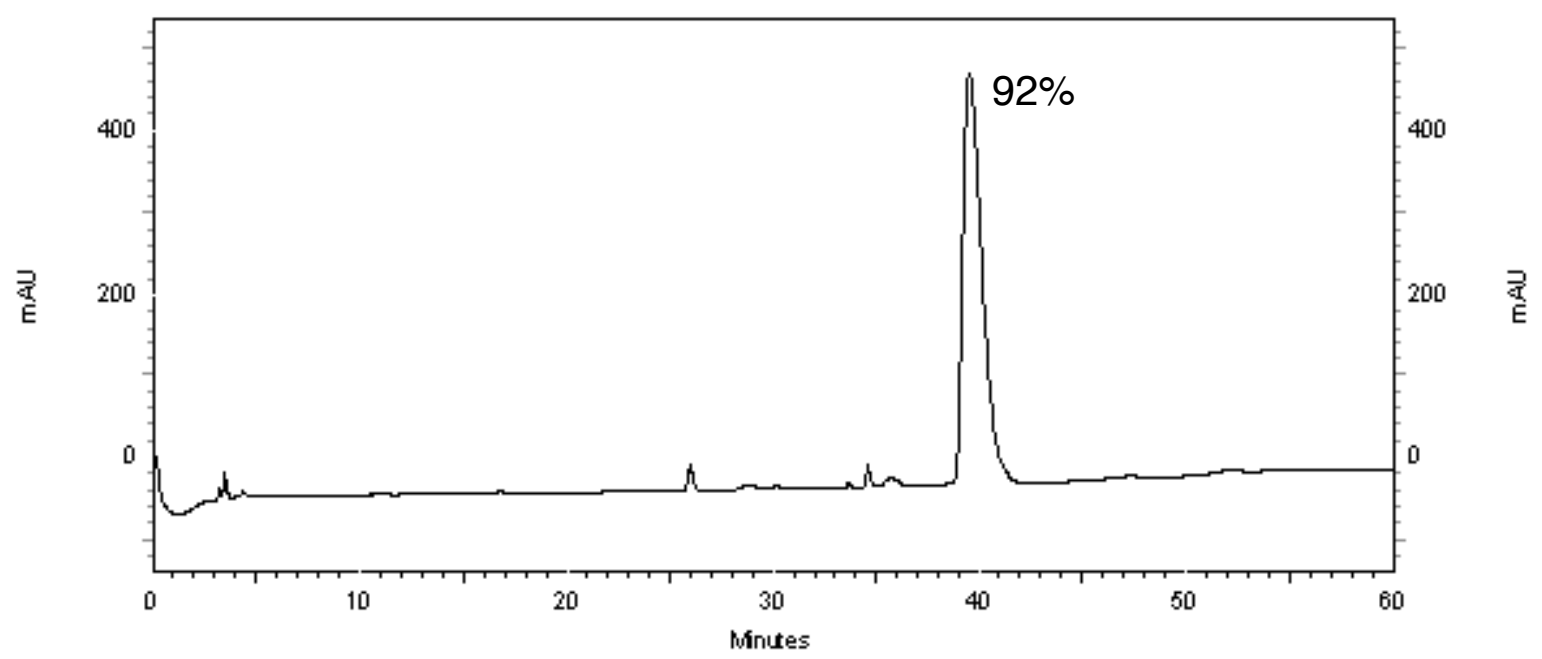


Gorske et al.

\section{9: (Nfpe) $)_{5}$, MW Conditions}

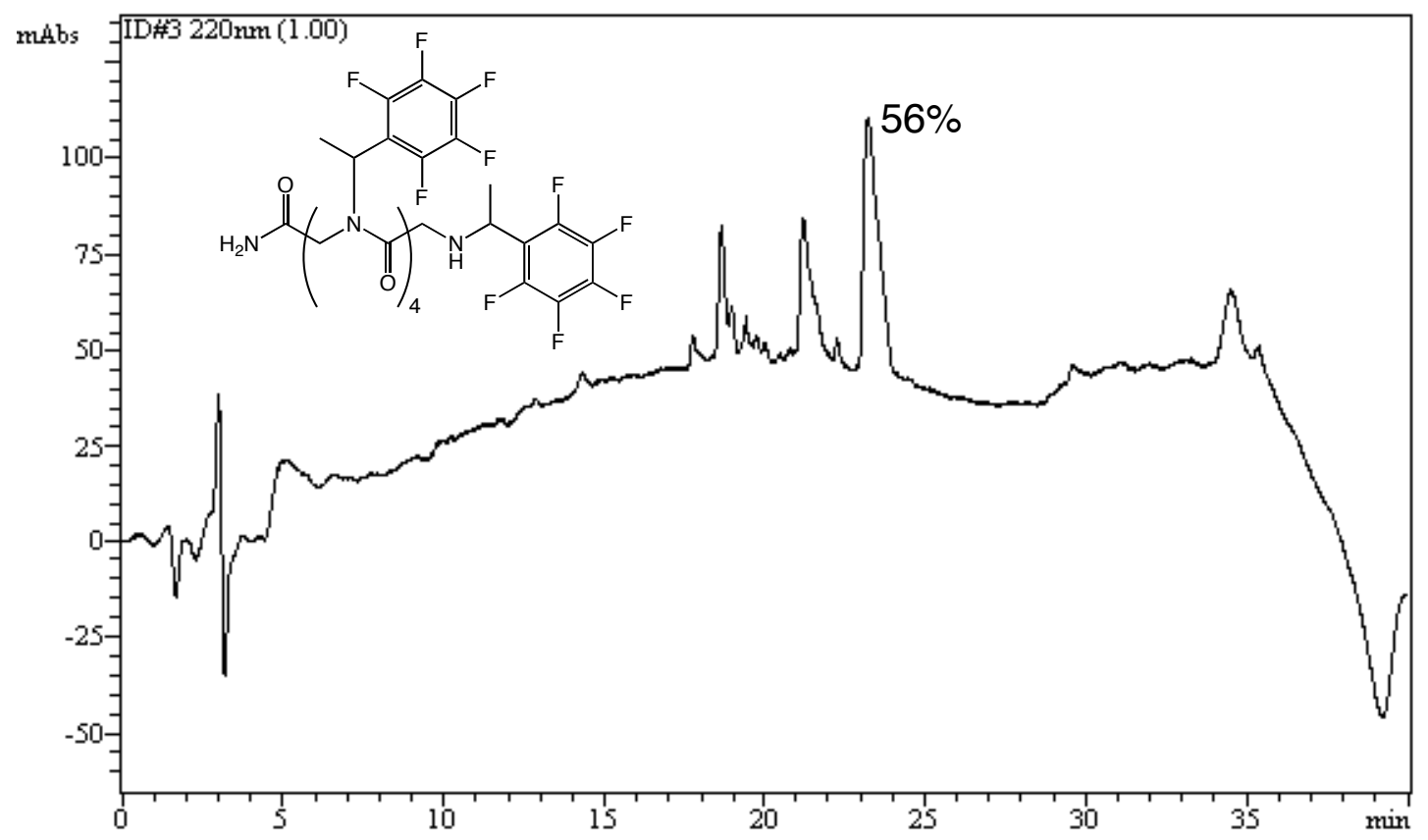

9: $(N \mathrm{fpe})_{5}, 25^{\circ} \mathrm{C}$ control

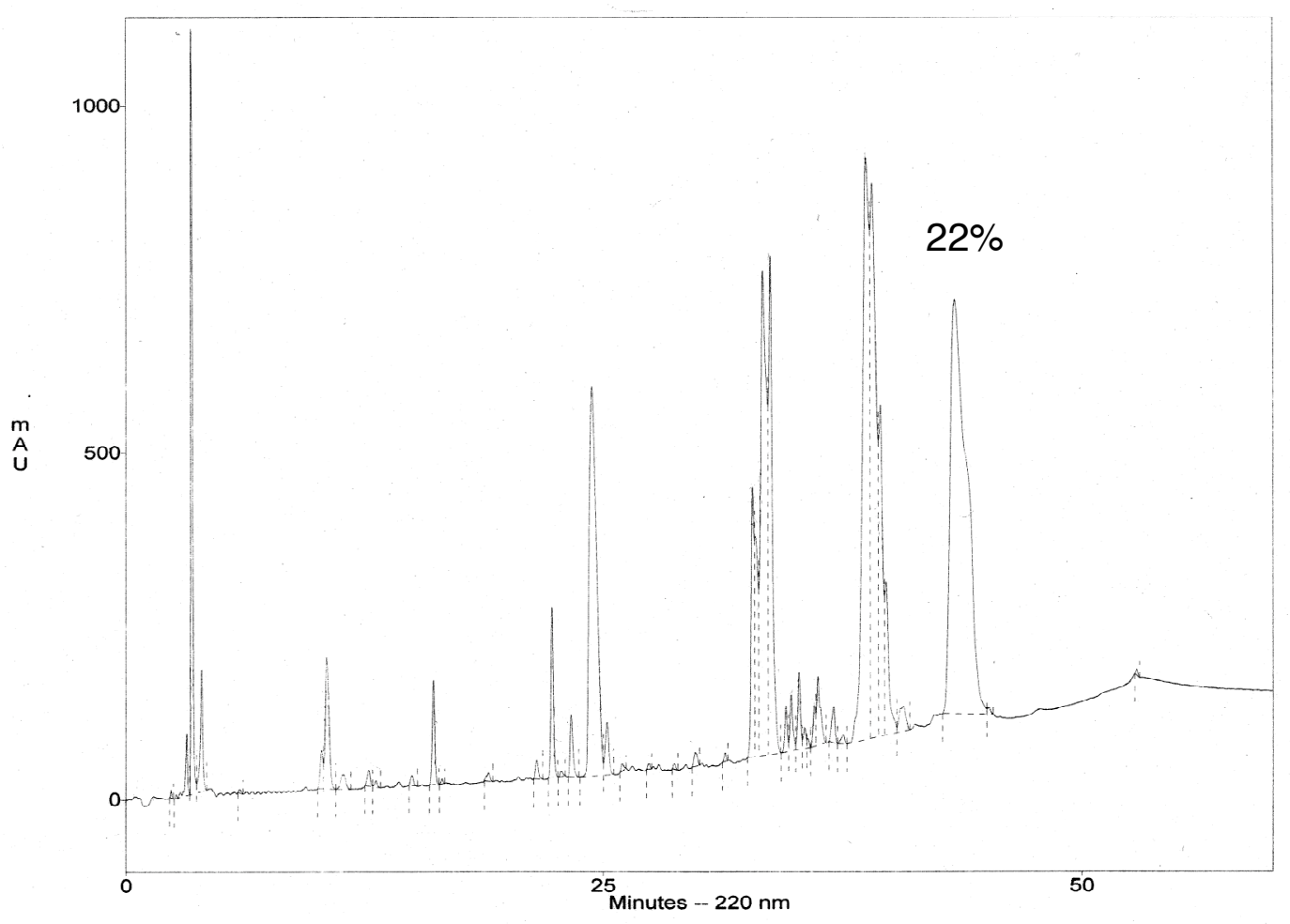


10: $(N 2 \mathrm{fb})_{5}$, MW Conditions

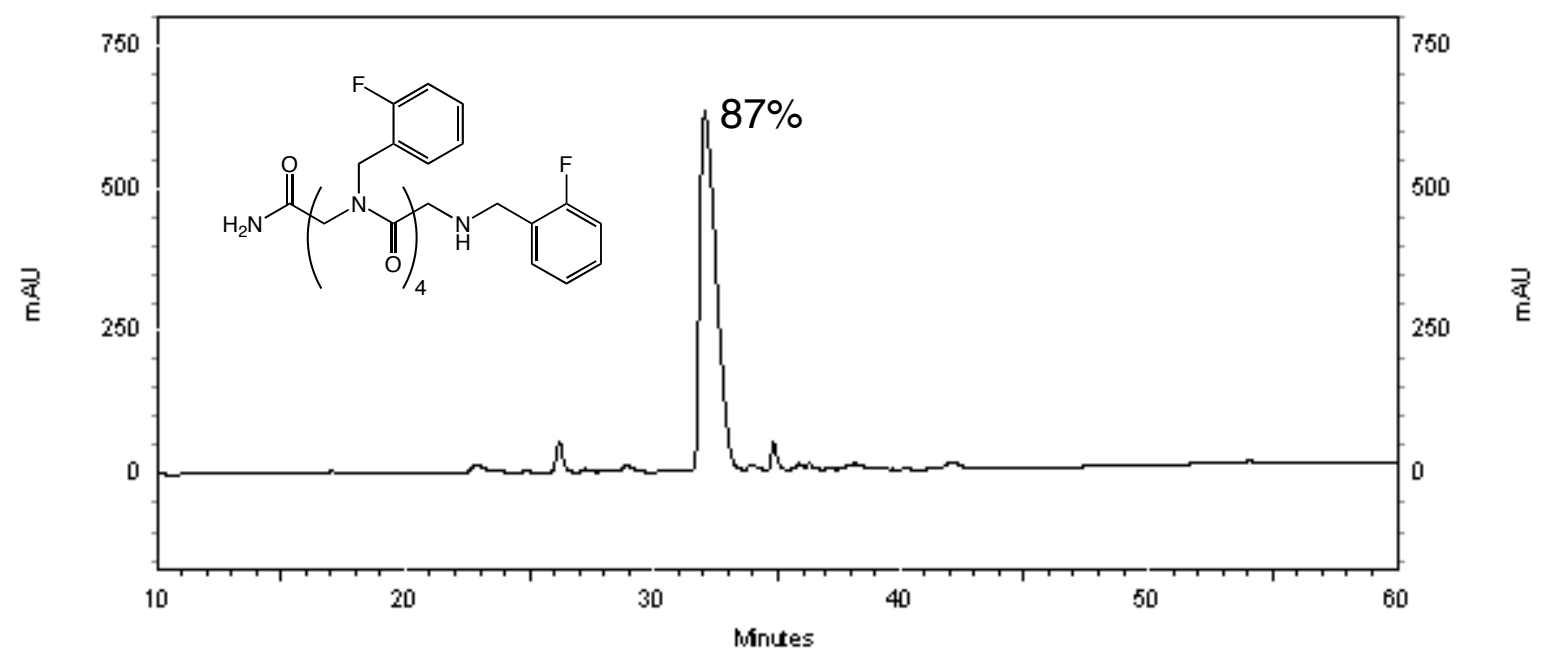

10: $(N 2 \mathrm{fb})_{5}, 25^{\circ} \mathrm{C}$ control

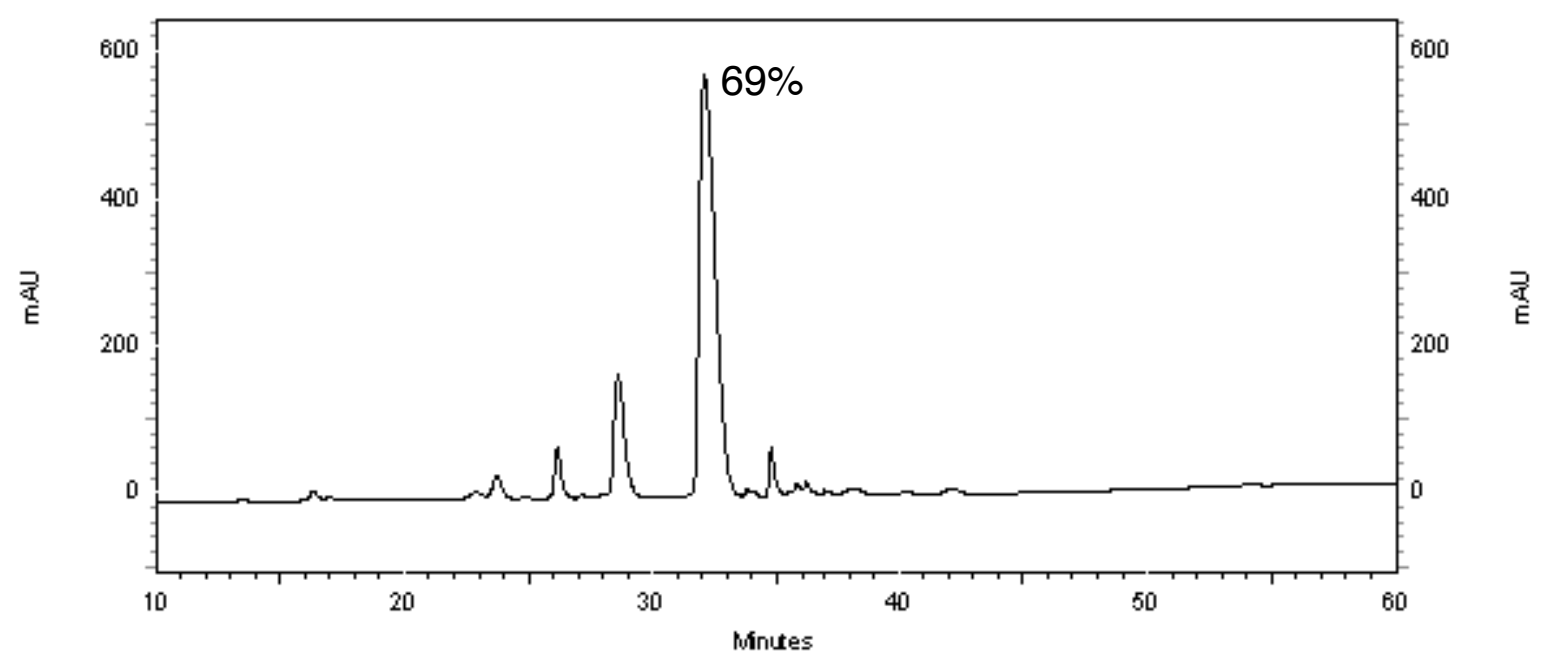


11: $(\mathrm{N} 3 \mathrm{fb})_{5}$, MW Conditions

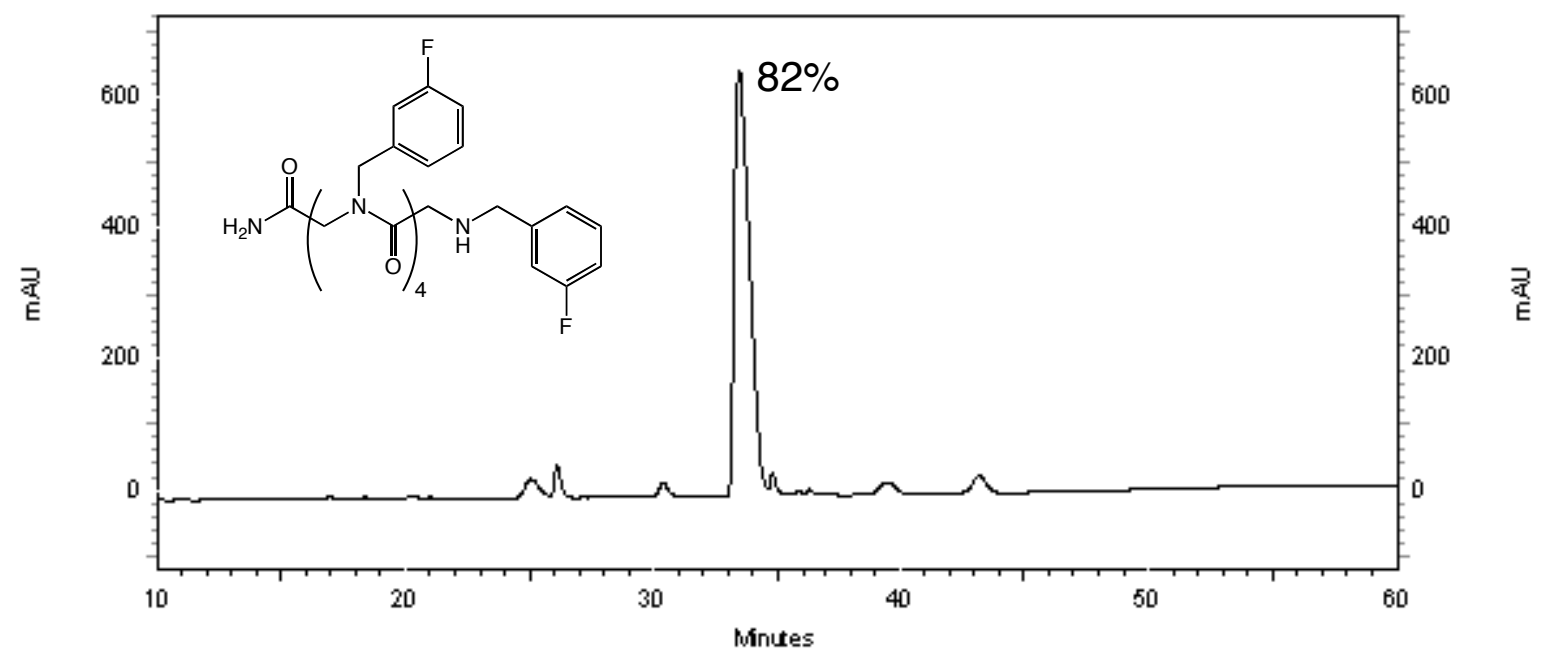

11: $(N 3 \mathrm{fb})_{5}, 25^{\circ} \mathrm{C}$ control

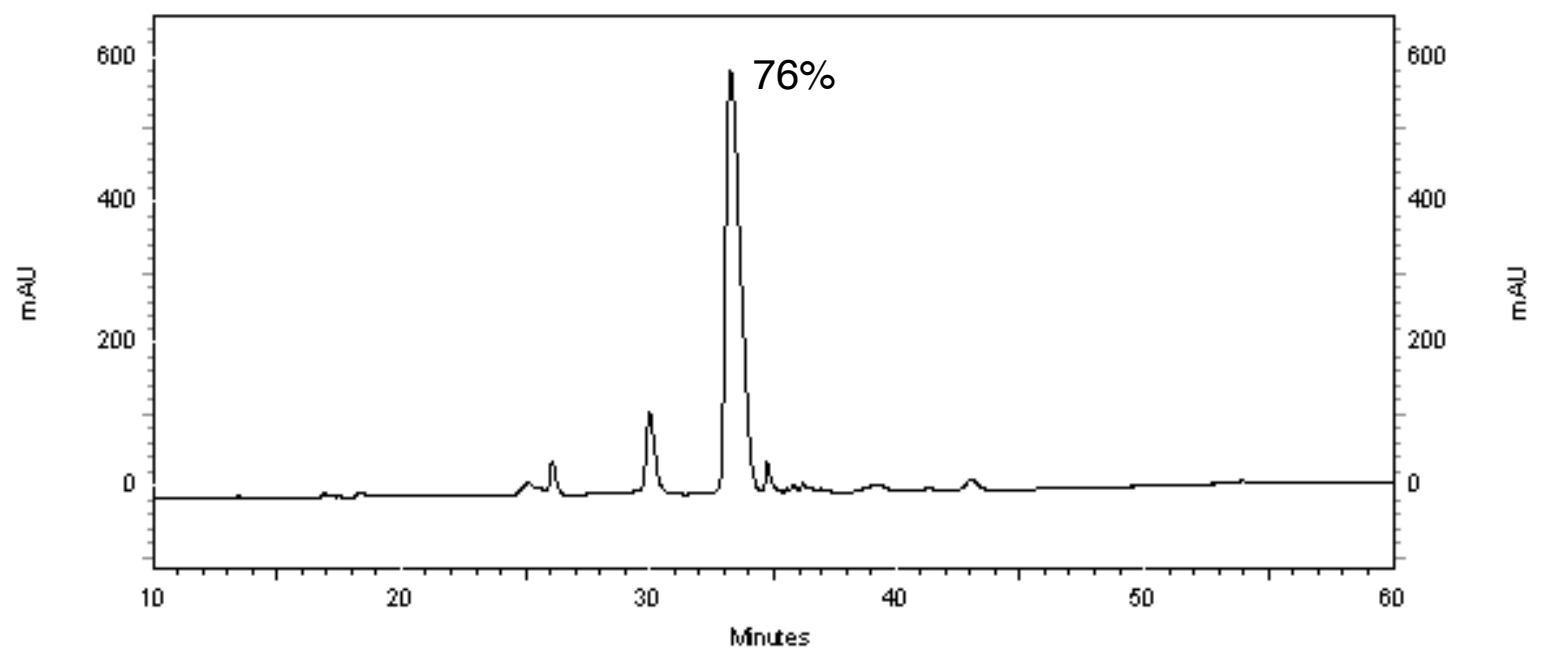


12: $(N 4 \mathrm{fb})_{5}$, MW Conditions

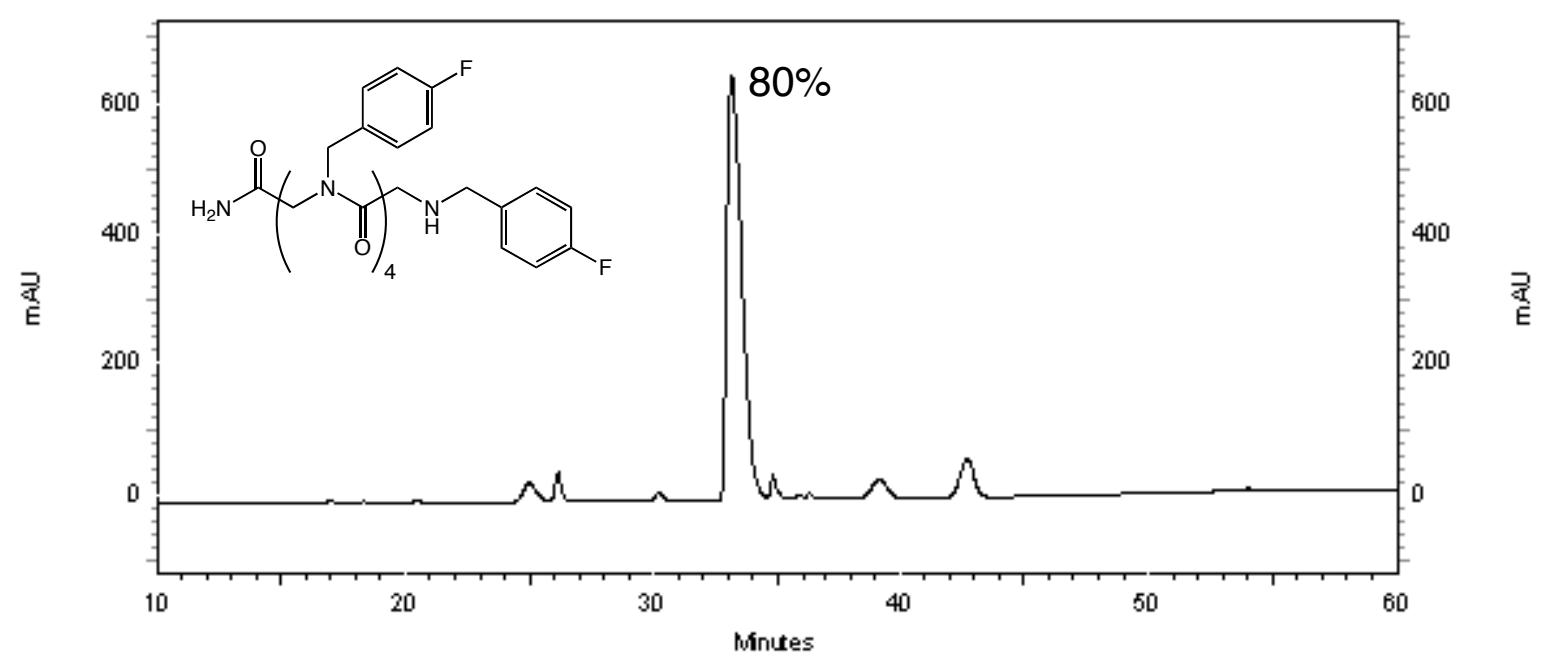

12: $(N 4 \mathrm{fb})_{5}, 25^{\circ} \mathrm{C}$ control

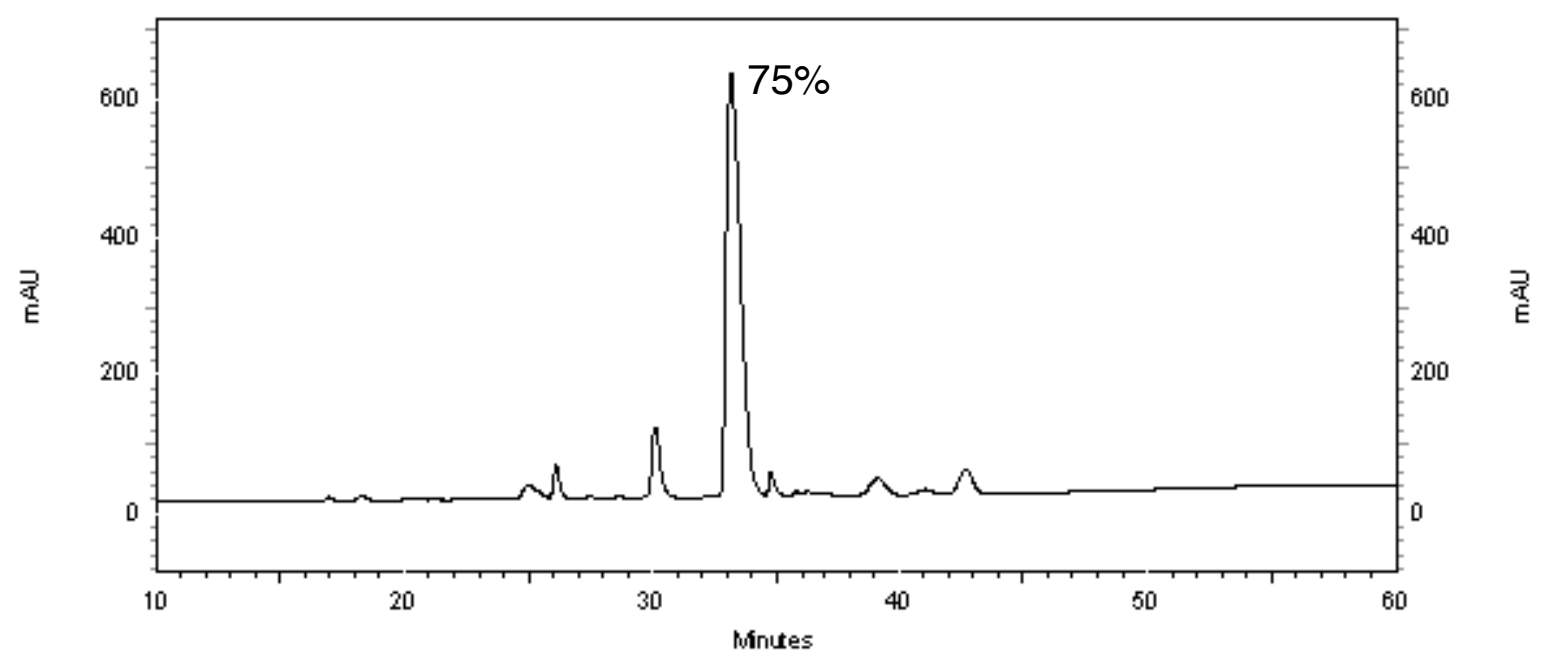


13: $(N 2,6 \mathrm{fb})_{5}$, MW Conditions

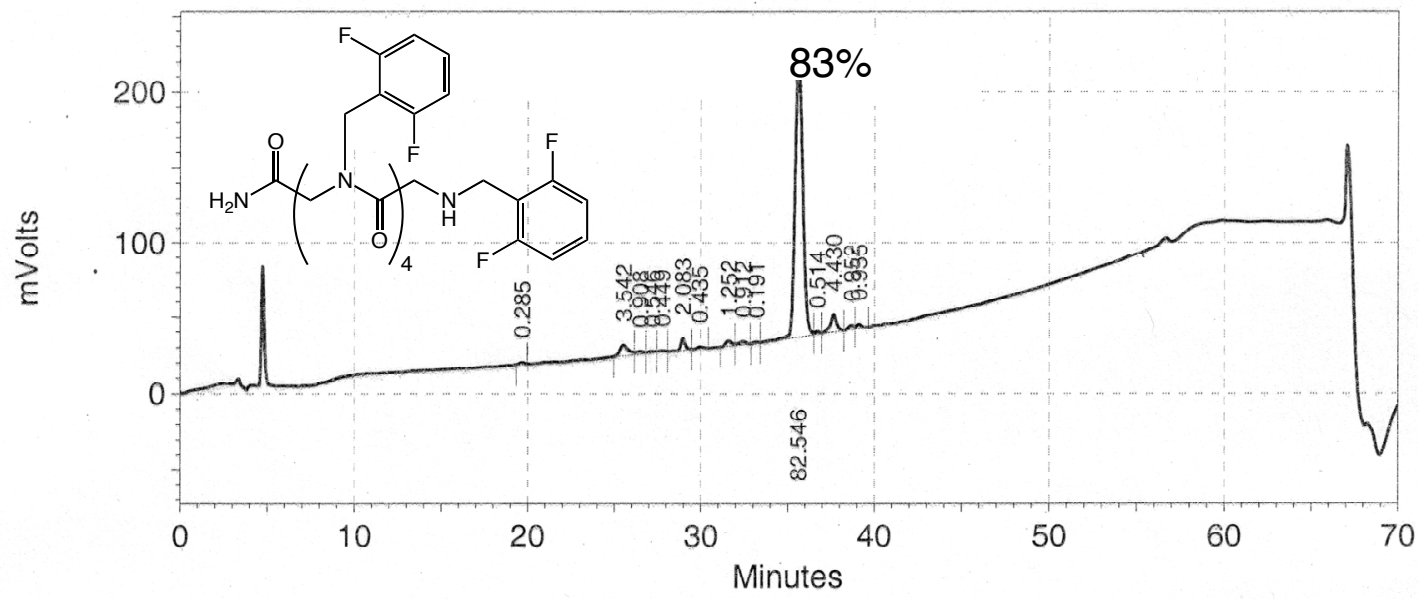

13: $(N 2,6 \mathrm{fb})_{5}, 25^{\circ} \mathrm{C}$ control

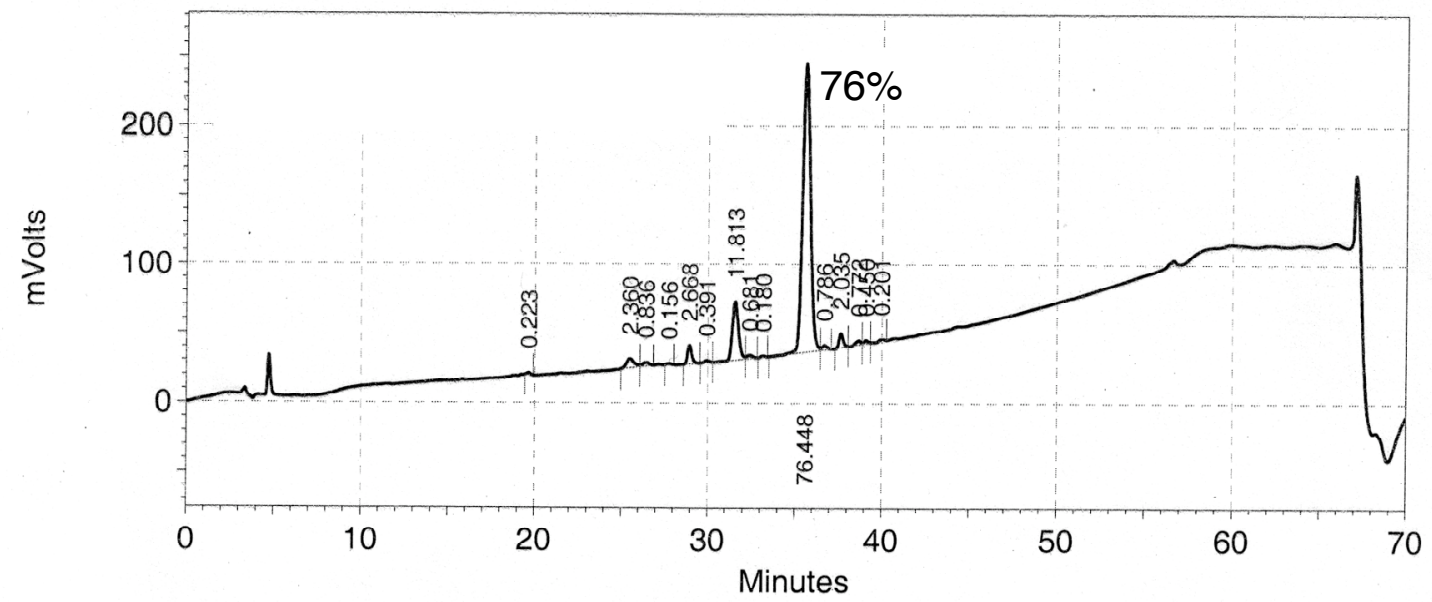


Gorske et al.

14: $(N 3,5 \mathrm{fb})_{5}$, MW Conditions

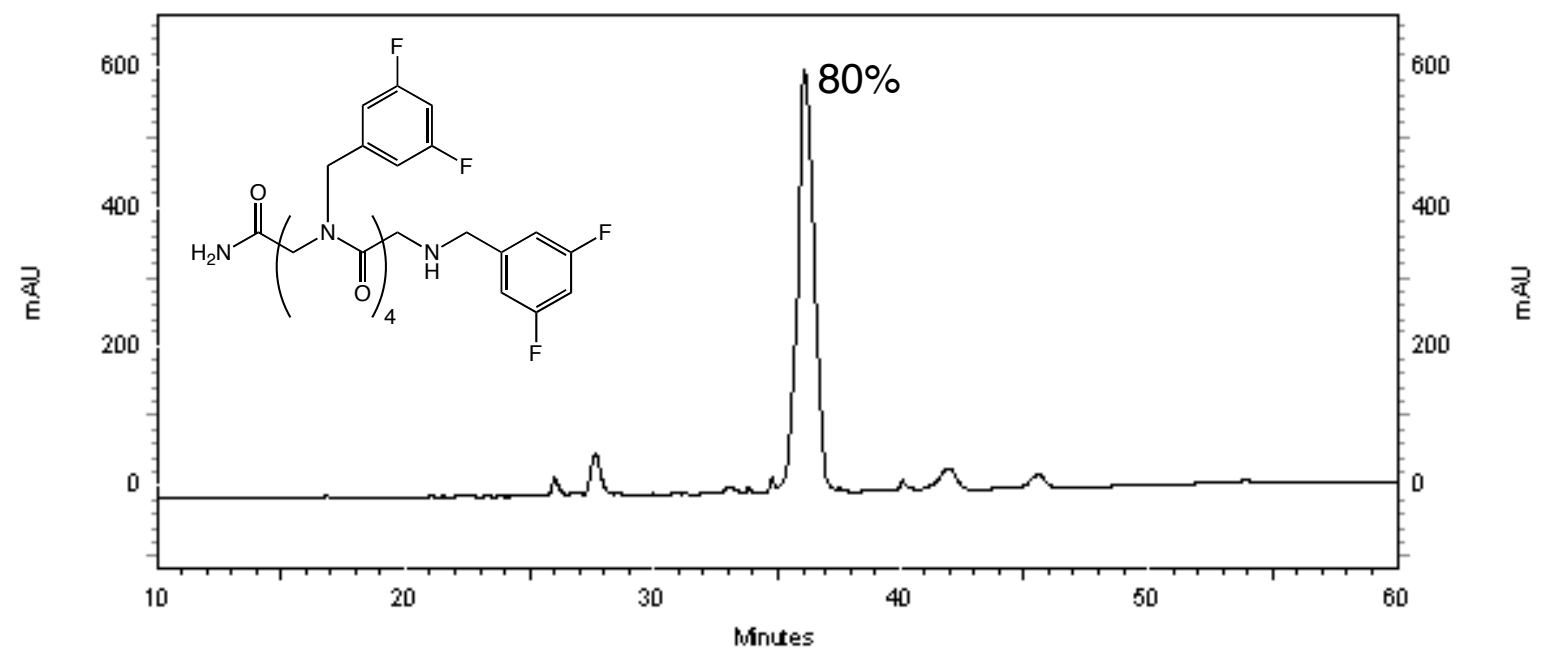

14: $(N 3,5 \mathrm{fb})_{5}, 25^{\circ} \mathrm{C}$ control

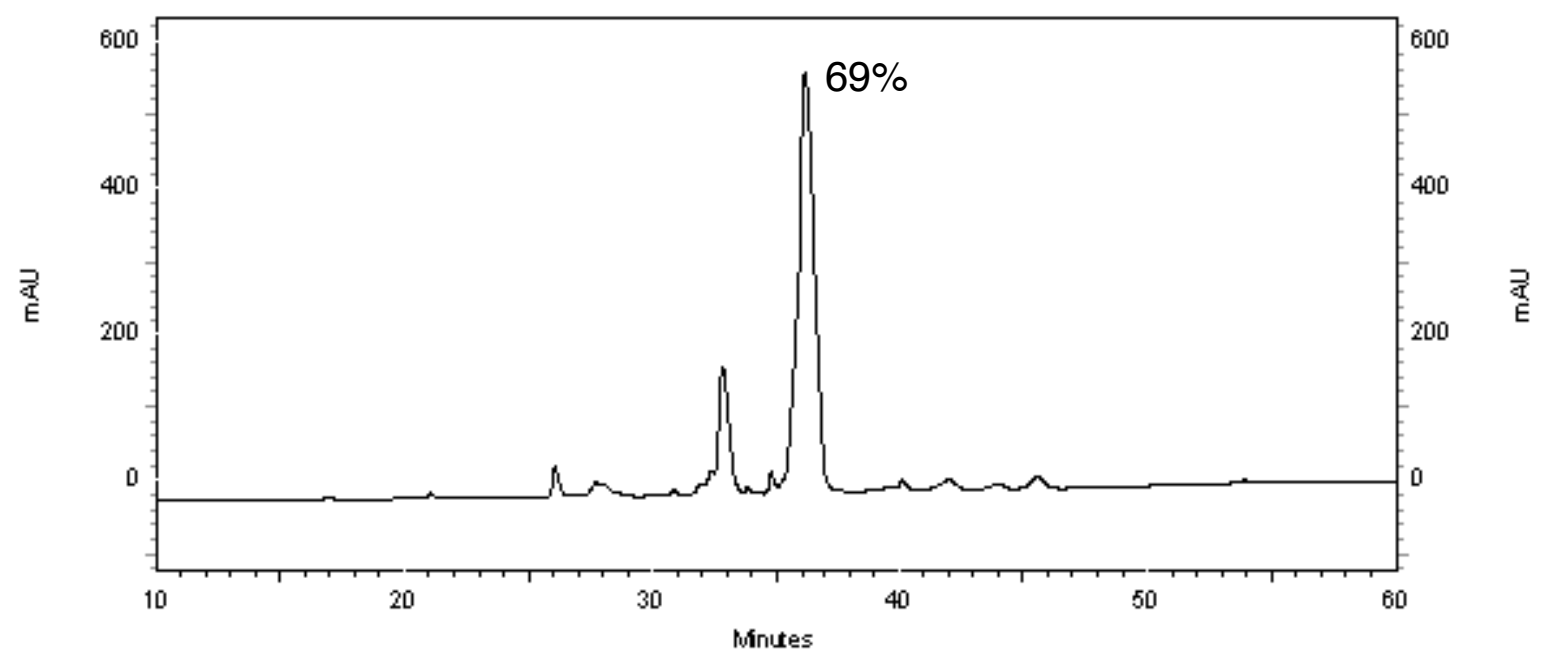


15: $(N 2 \mathrm{nb})_{5}, \mathrm{MW}$ Conditions

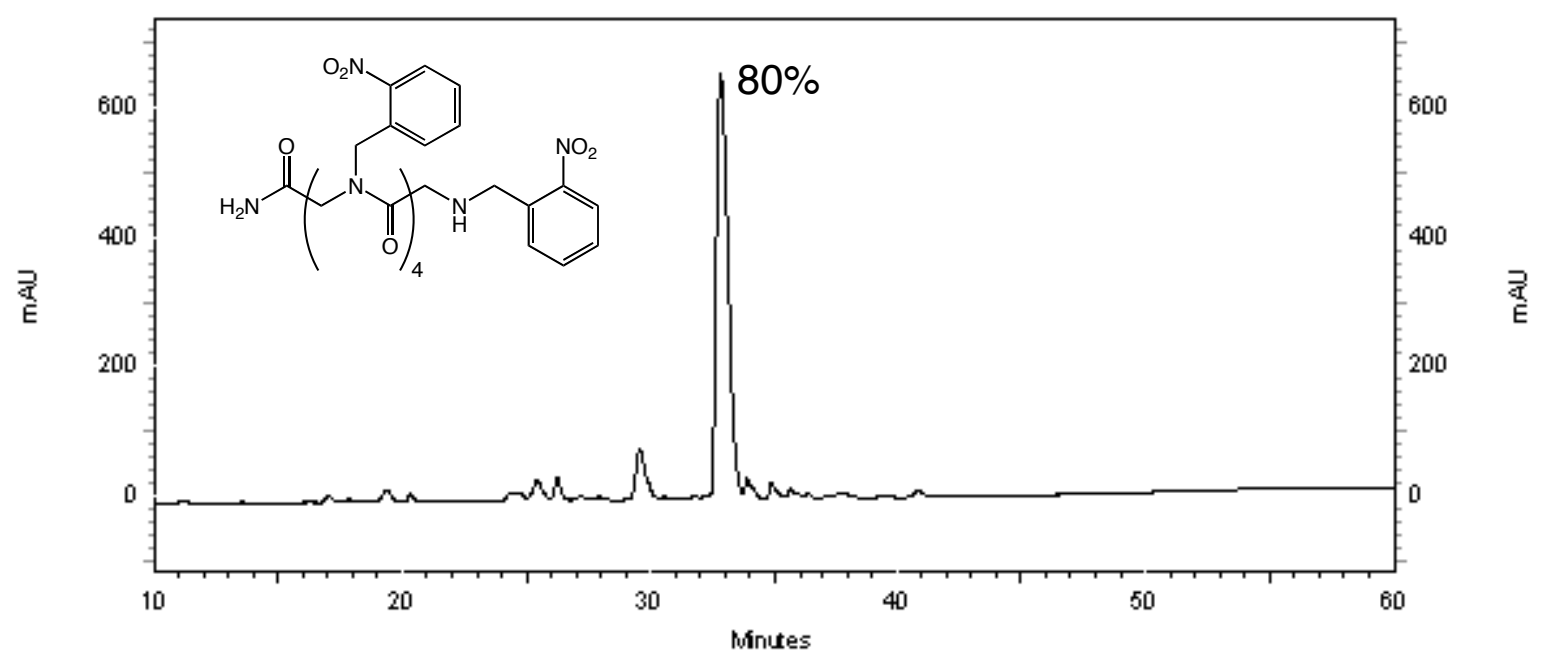

15: $(N 2 \mathrm{nb})_{5}, 25{ }^{\circ} \mathrm{C}$ control

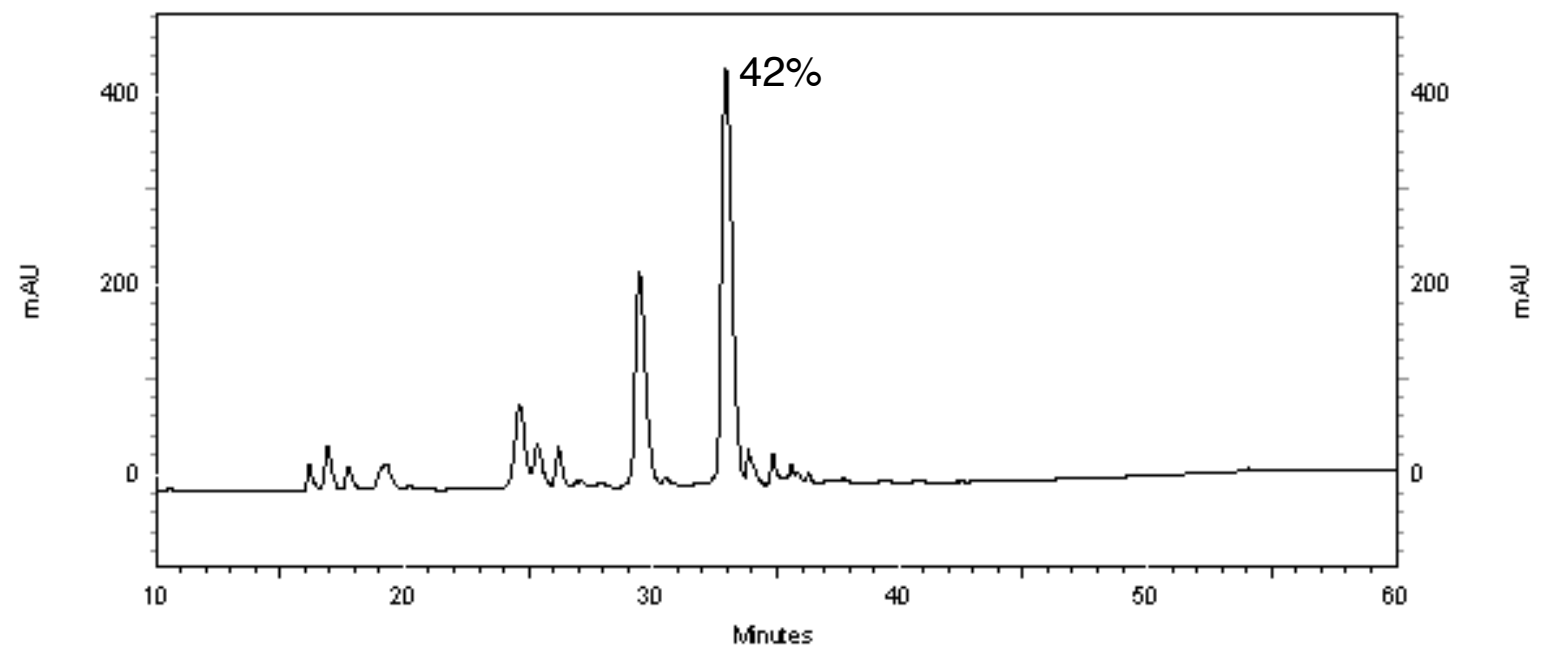


16: $(N 3 \mathrm{nb})_{5}$, MW Conditions

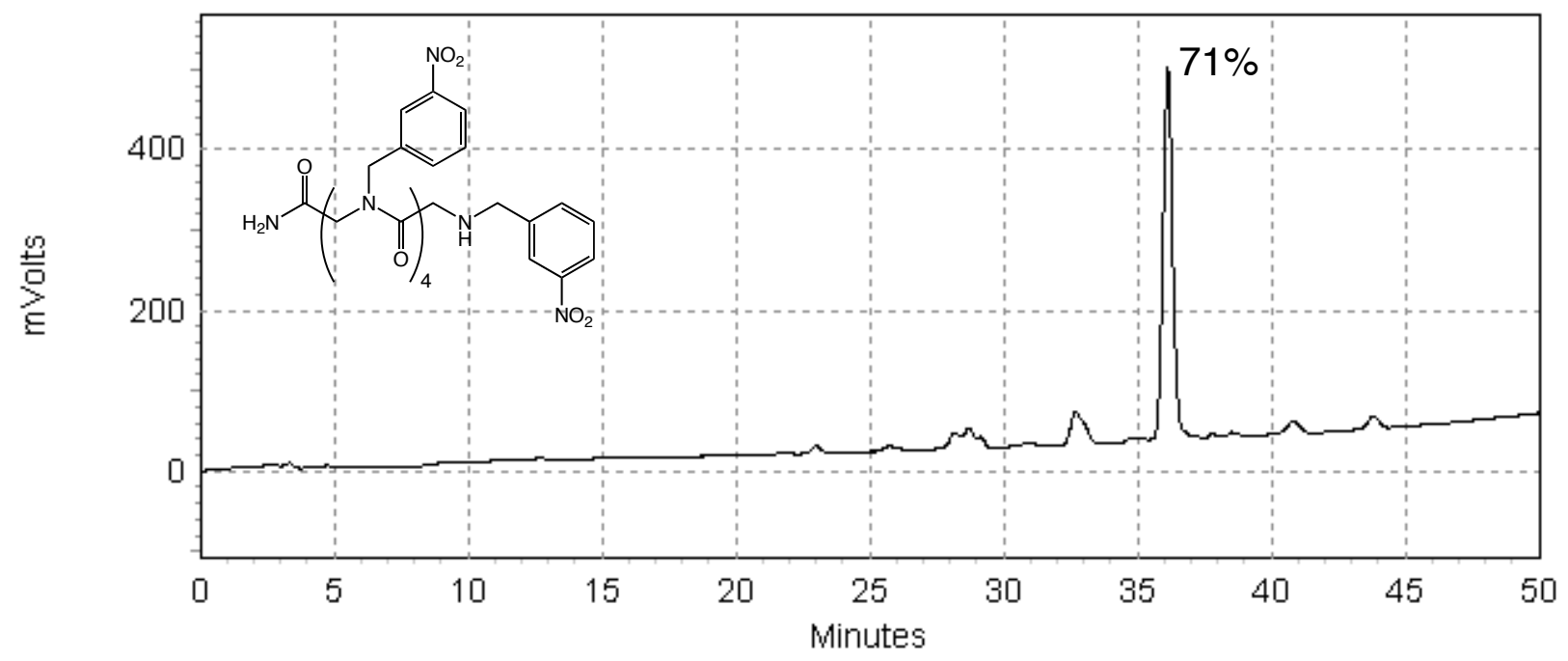

16: $(\mathrm{N} 3 \mathrm{nb})_{5}, 25^{\circ} \mathrm{C}$ control

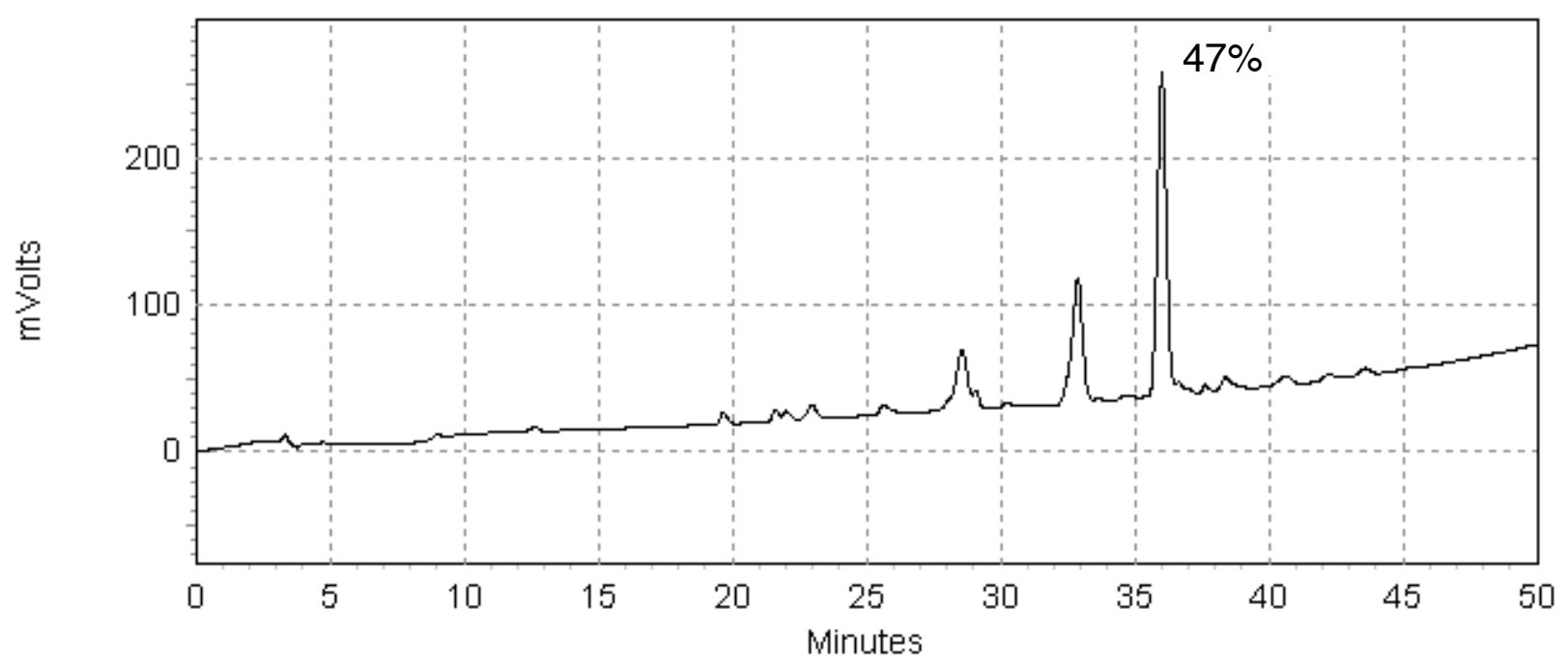


Gorske et al.

17: $(N 4 n b)_{5}$, MW Conditions

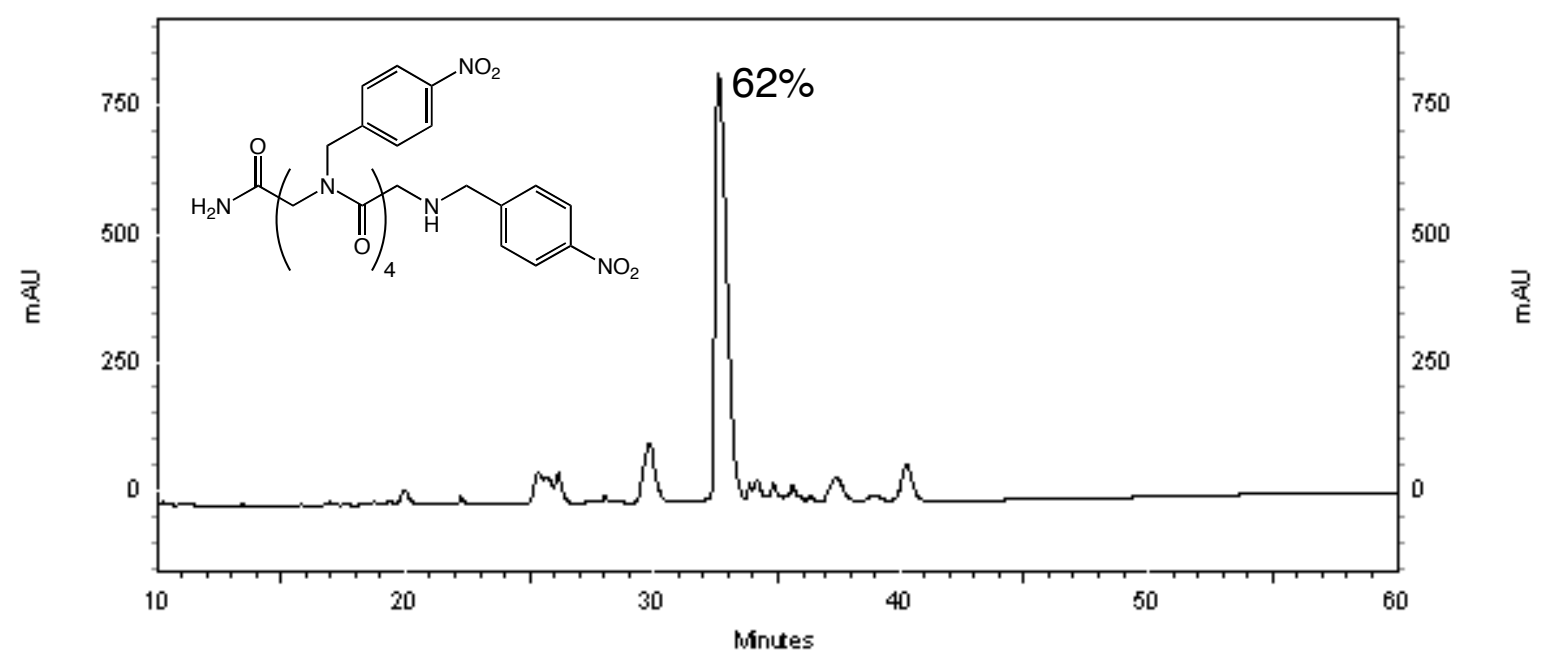

17: $(N 4 \mathrm{nb})_{5}, 25^{\circ} \mathrm{C}$ control

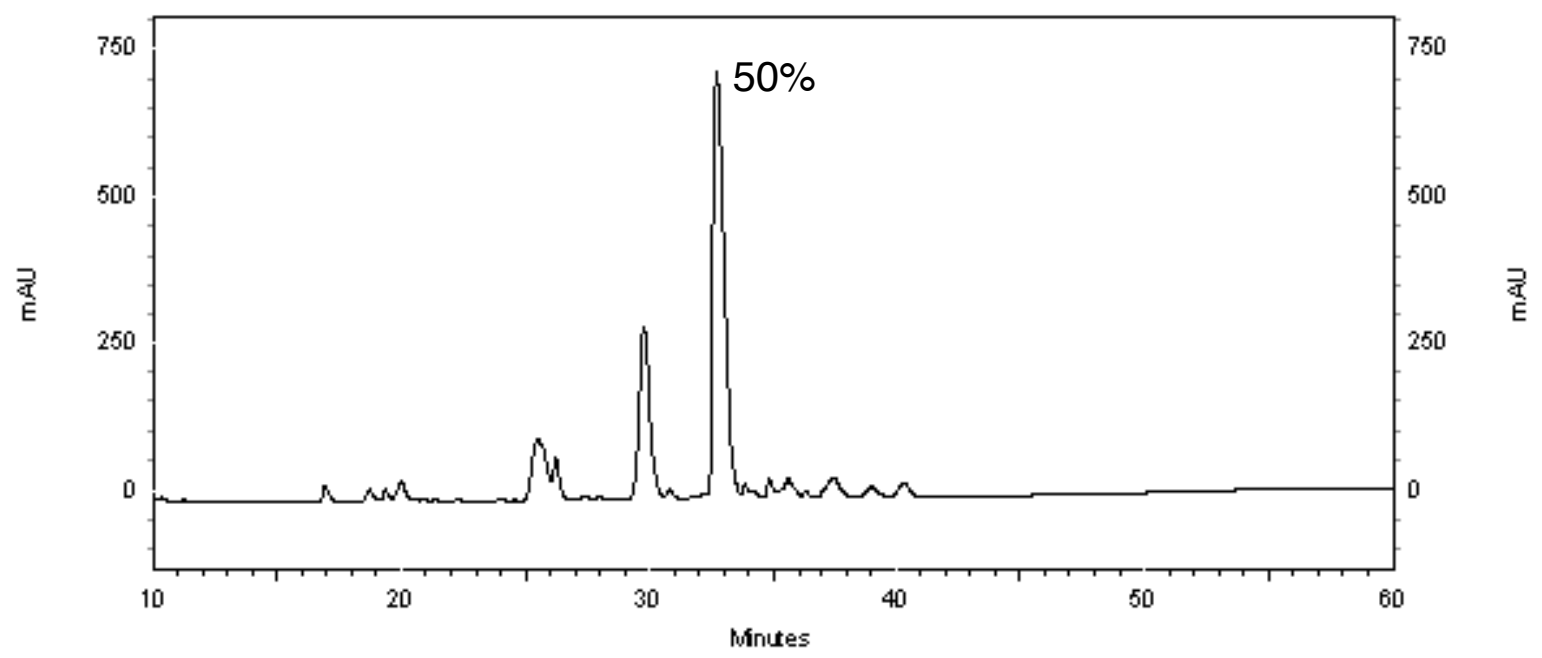


18: $(\mathrm{N} 2 \mathrm{mb})_{5}, \mathrm{MW}$ Conditions

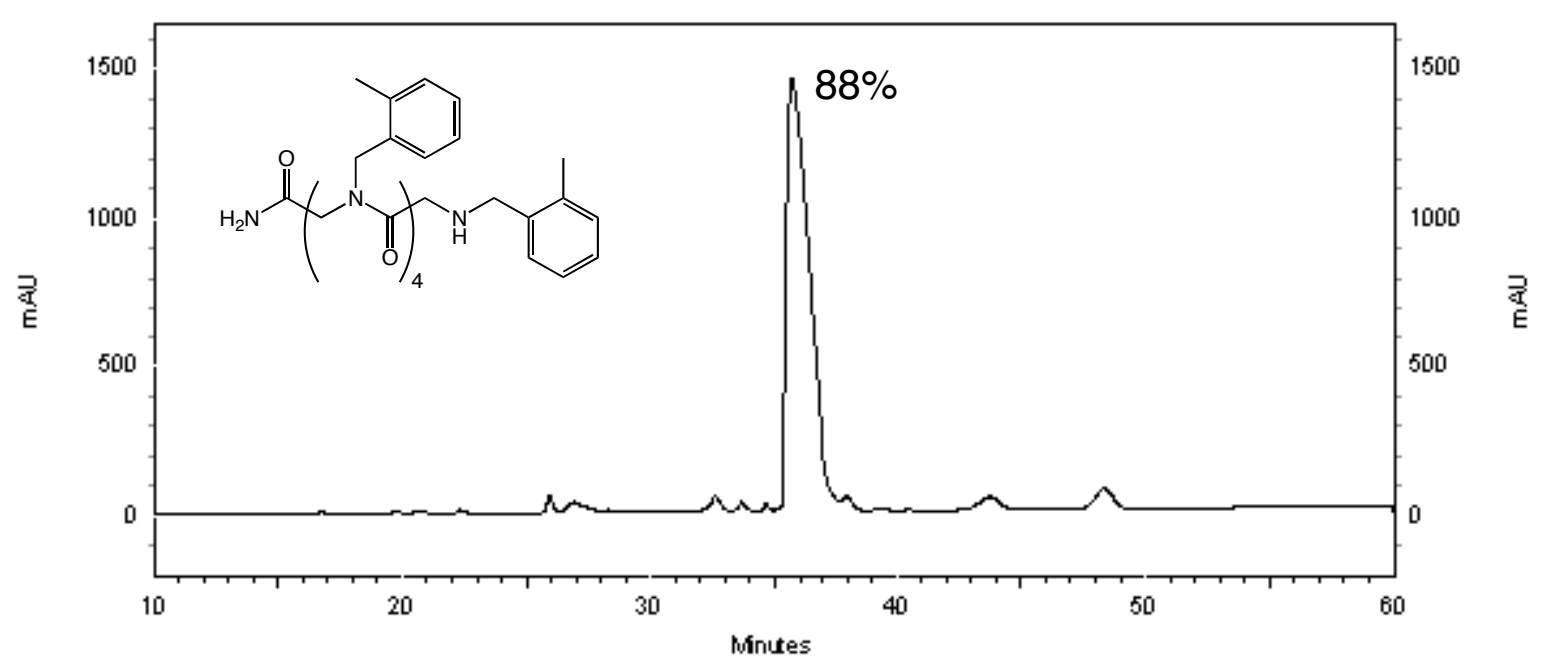

18: $(\mathrm{N} 2 \mathrm{mb})_{5}, 25{ }^{\circ} \mathrm{C}$ control

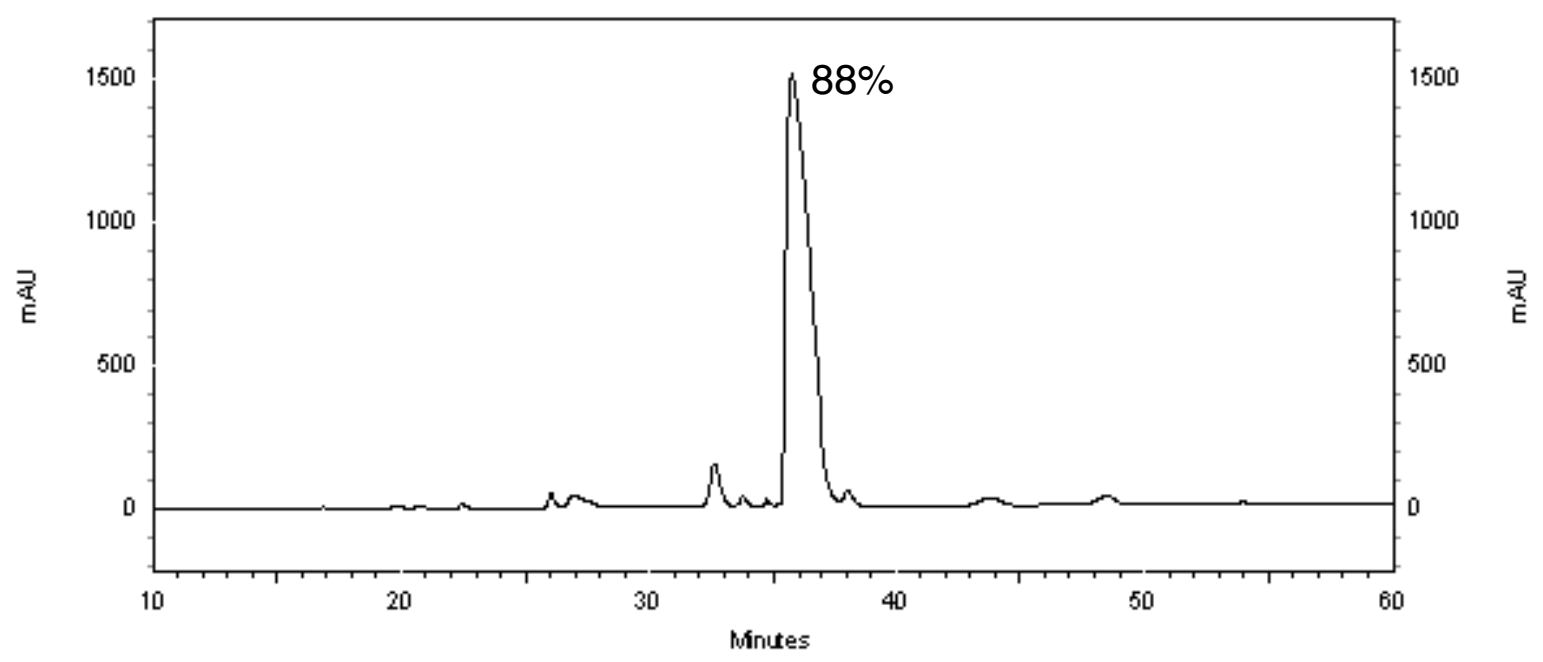


Gorske et al.

19: $(N 4 \mathrm{mob})_{5}, \mathrm{MW}$ Conditions

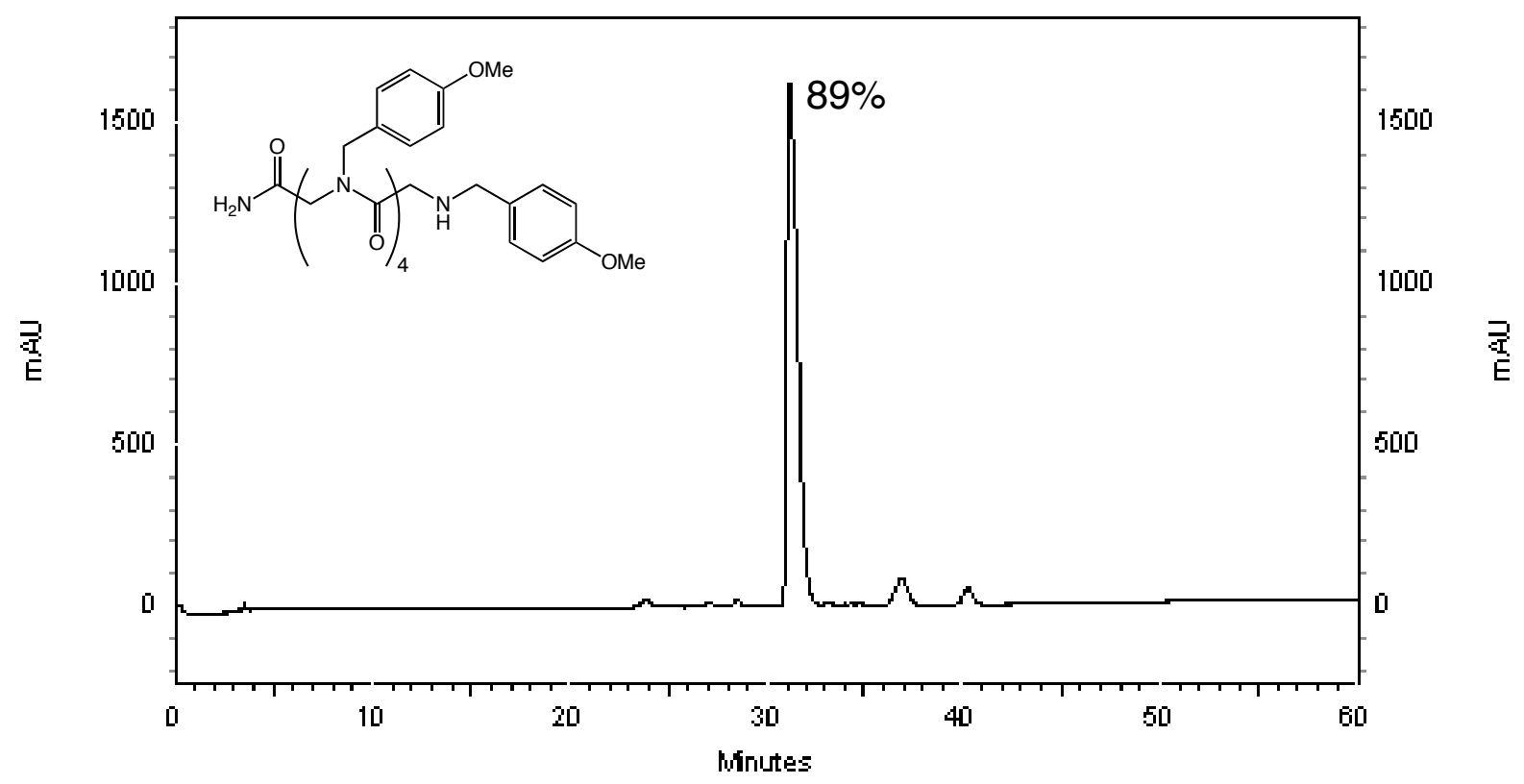

19: $(N 4 \mathrm{mob})_{5}, 25^{\circ} \mathrm{C}$ control

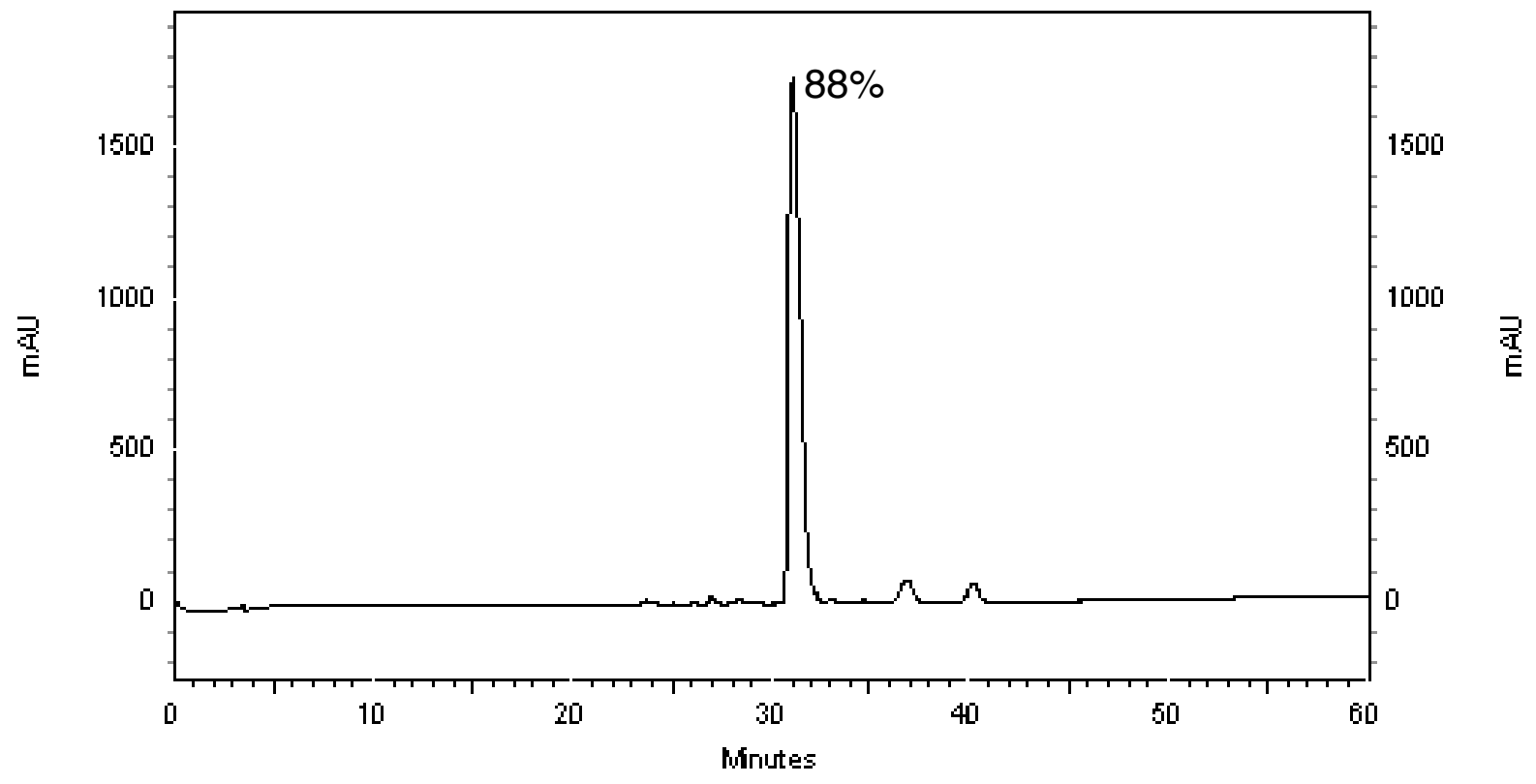


(Naniline) $)_{5}$, MW Conditions

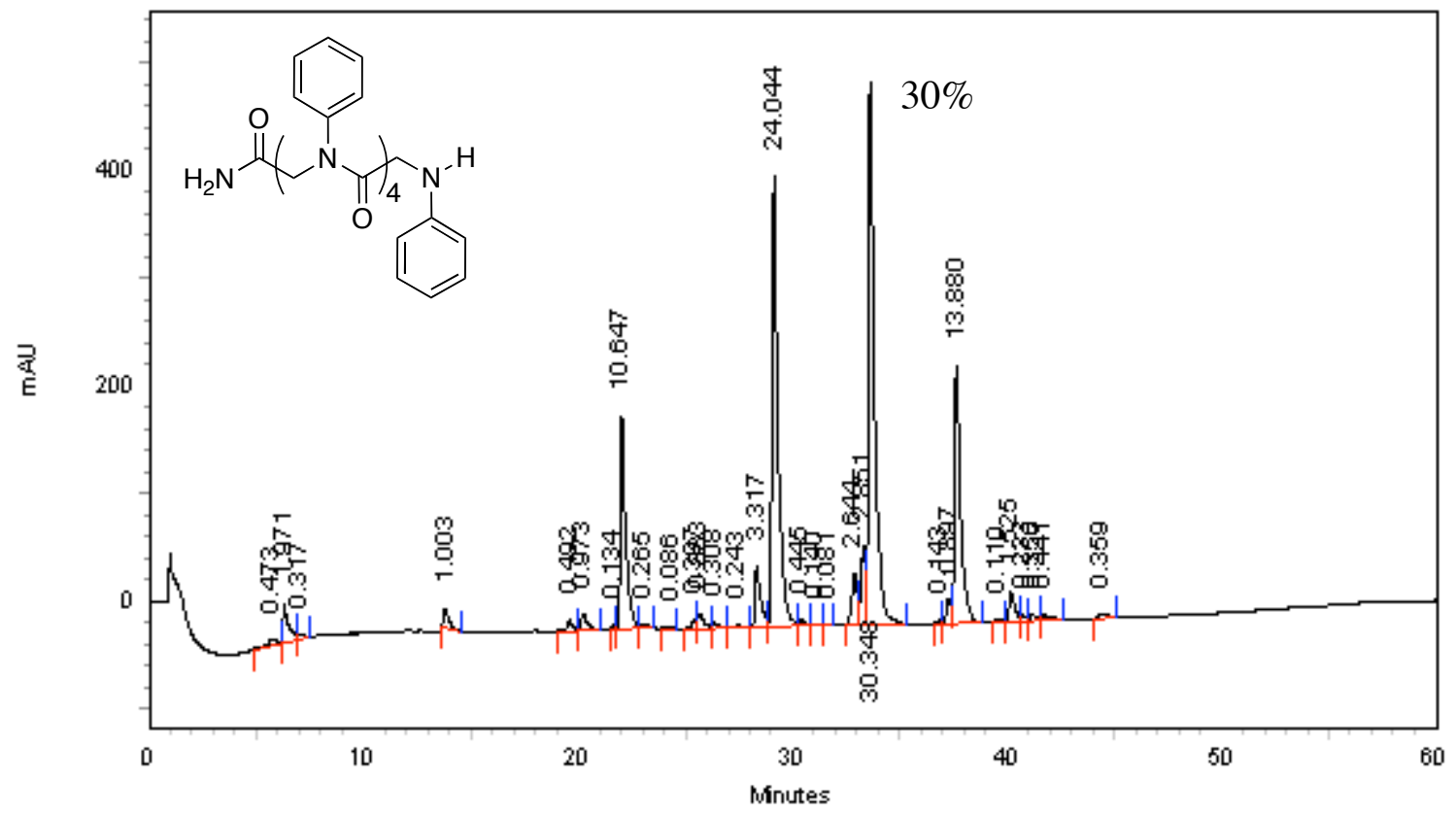

(Naniline) $)_{5}, 25^{\circ} \mathrm{C}$ control

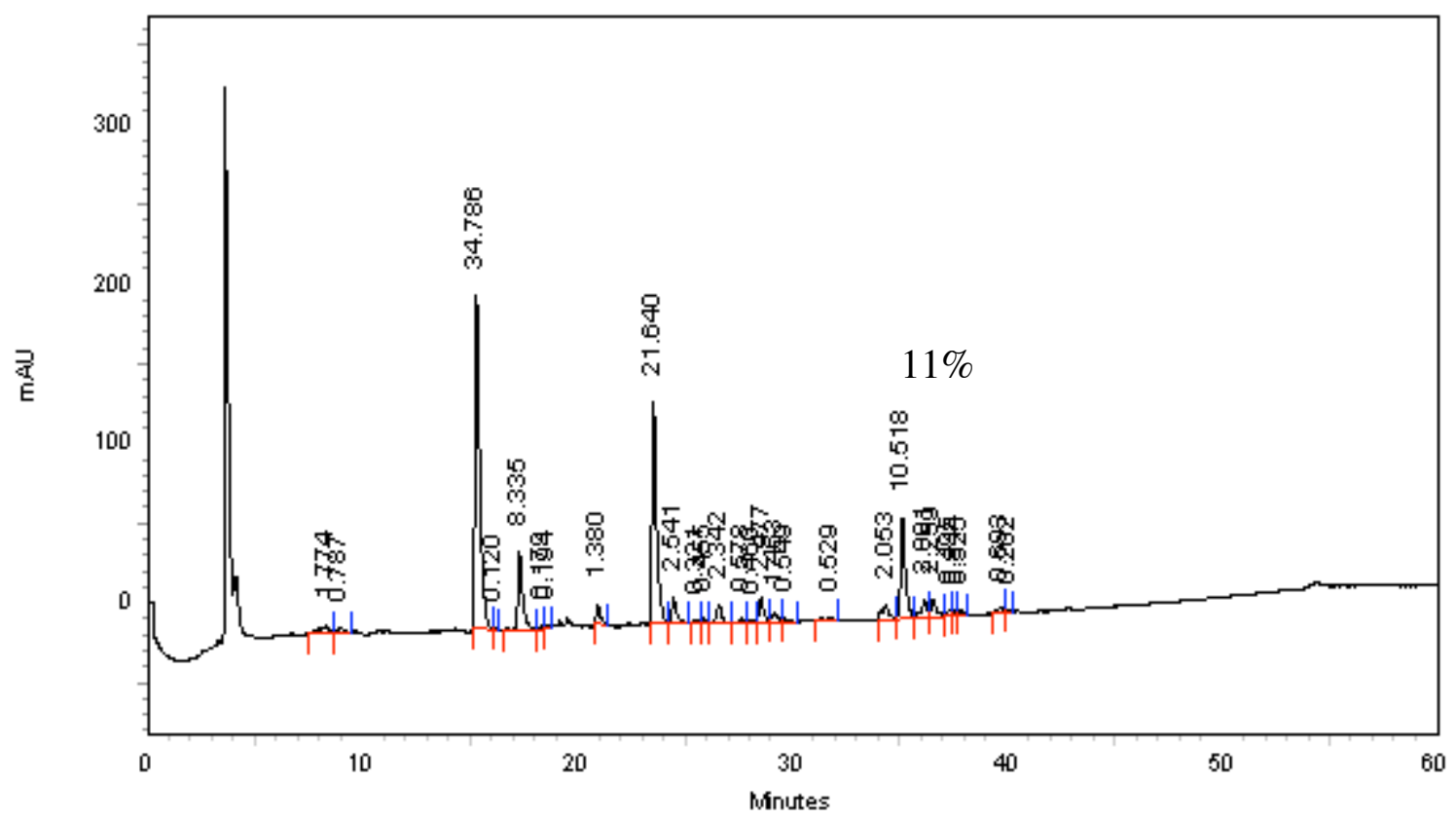


Gorske et al.

20: [(Nspe/N2nb ${ }_{4} N$ spe], MW Conditions

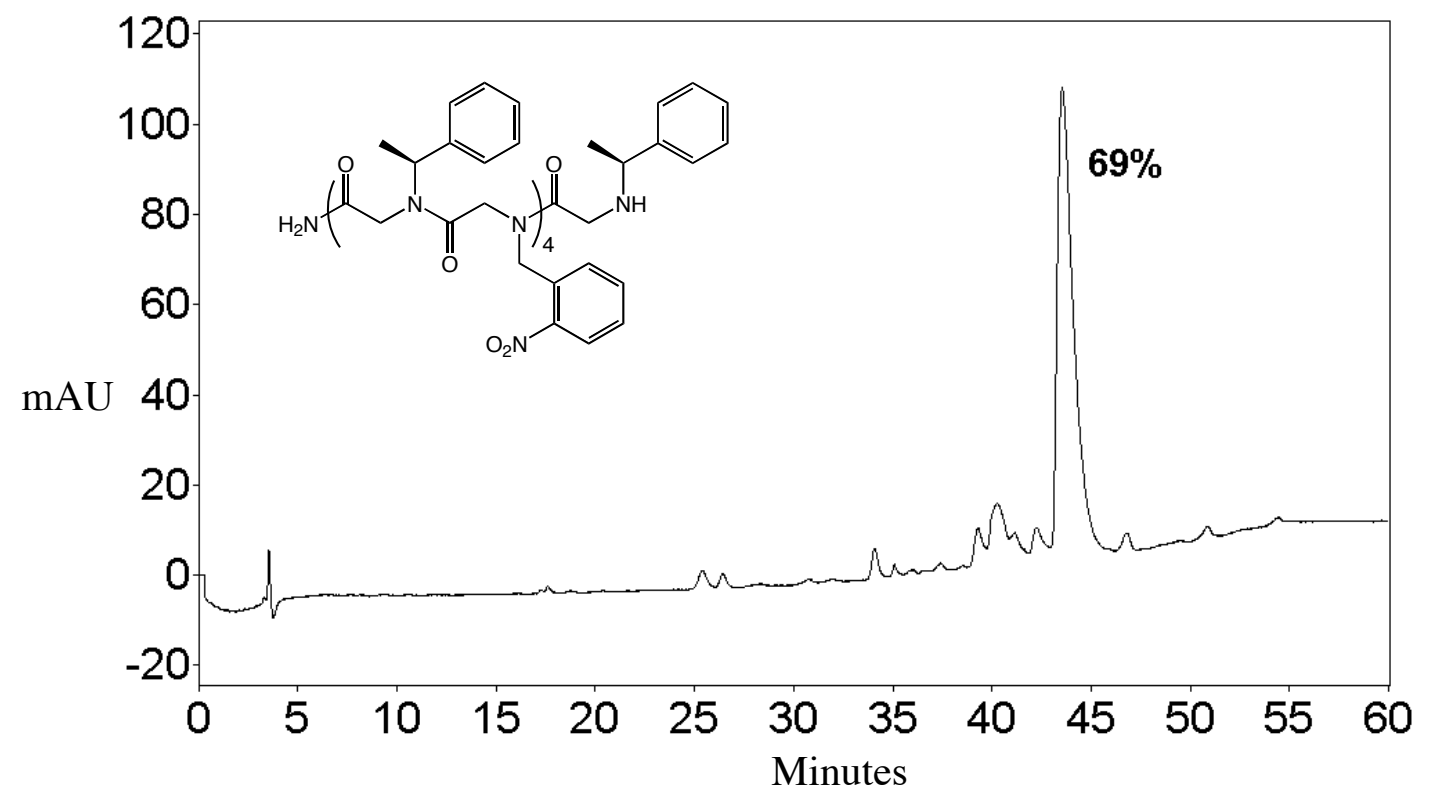

20: $\left[(N \text { spe } / N 2 \mathrm{nb})_{4} N\right.$ spe $], 25^{\circ} \mathrm{C}$ control

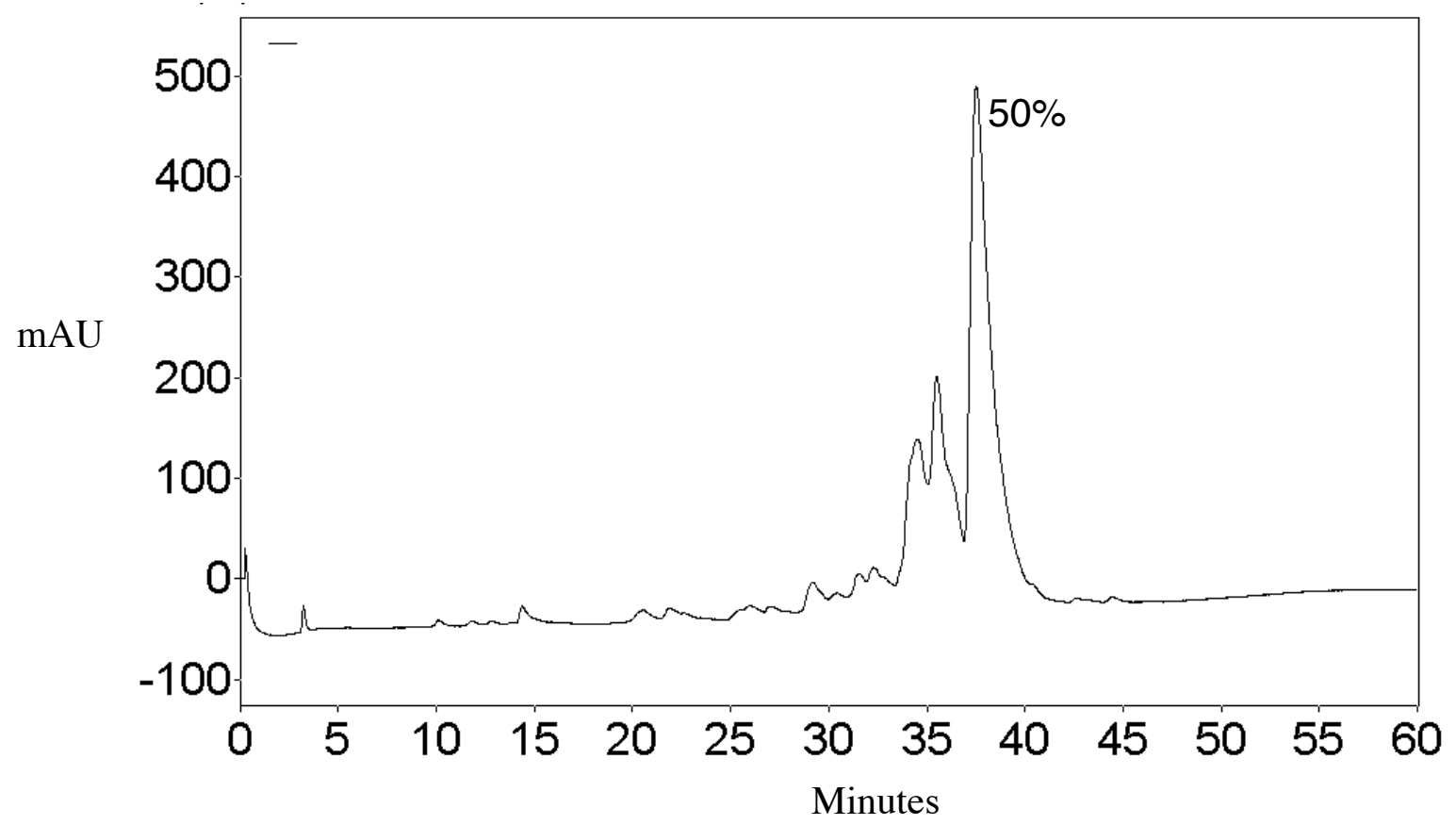


21: (Nspe/Nspe/N2nb) ${ }_{3}$, MW Conditions

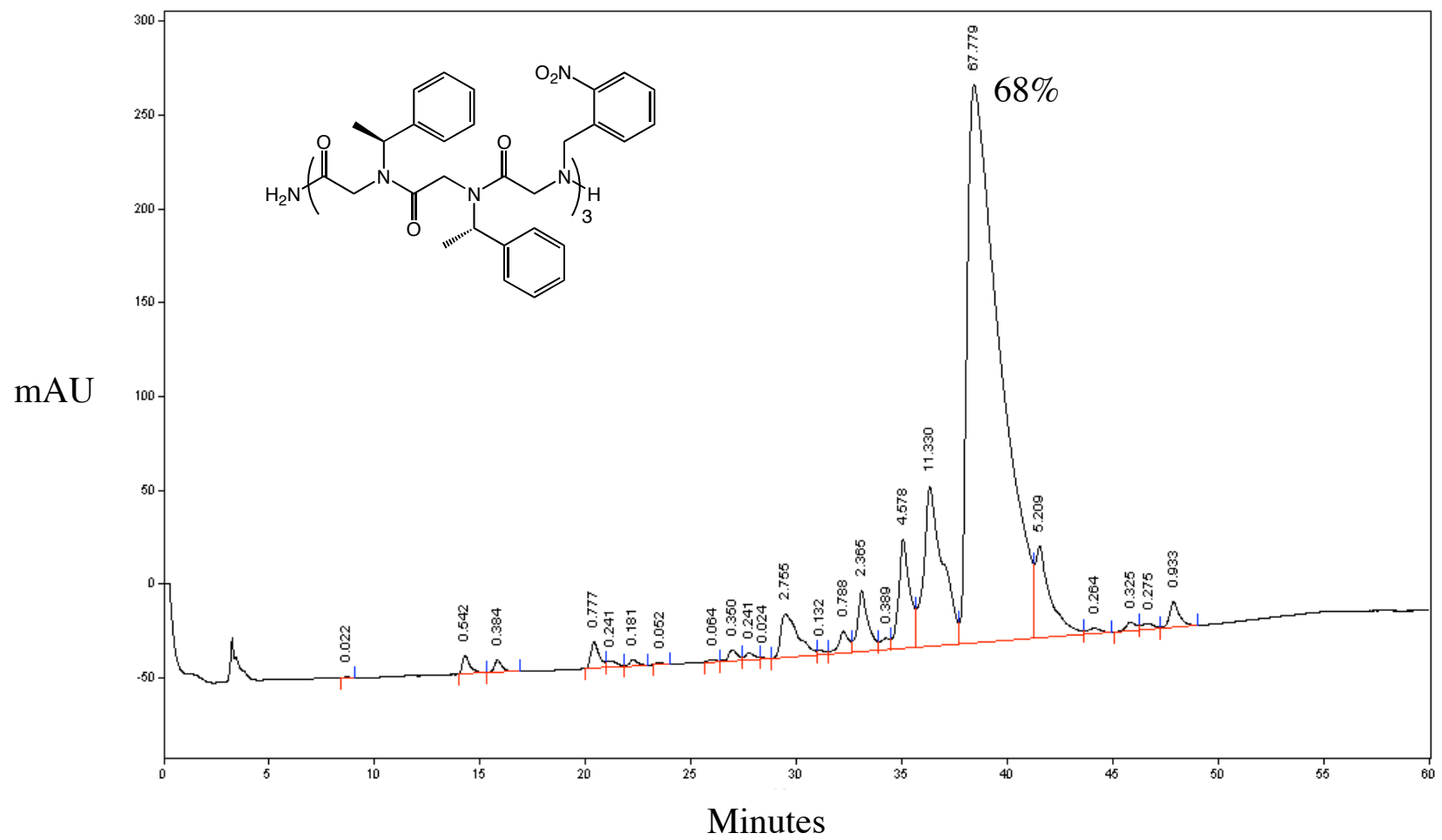

22: (Nspe) $)_{9}$, MW Conditions

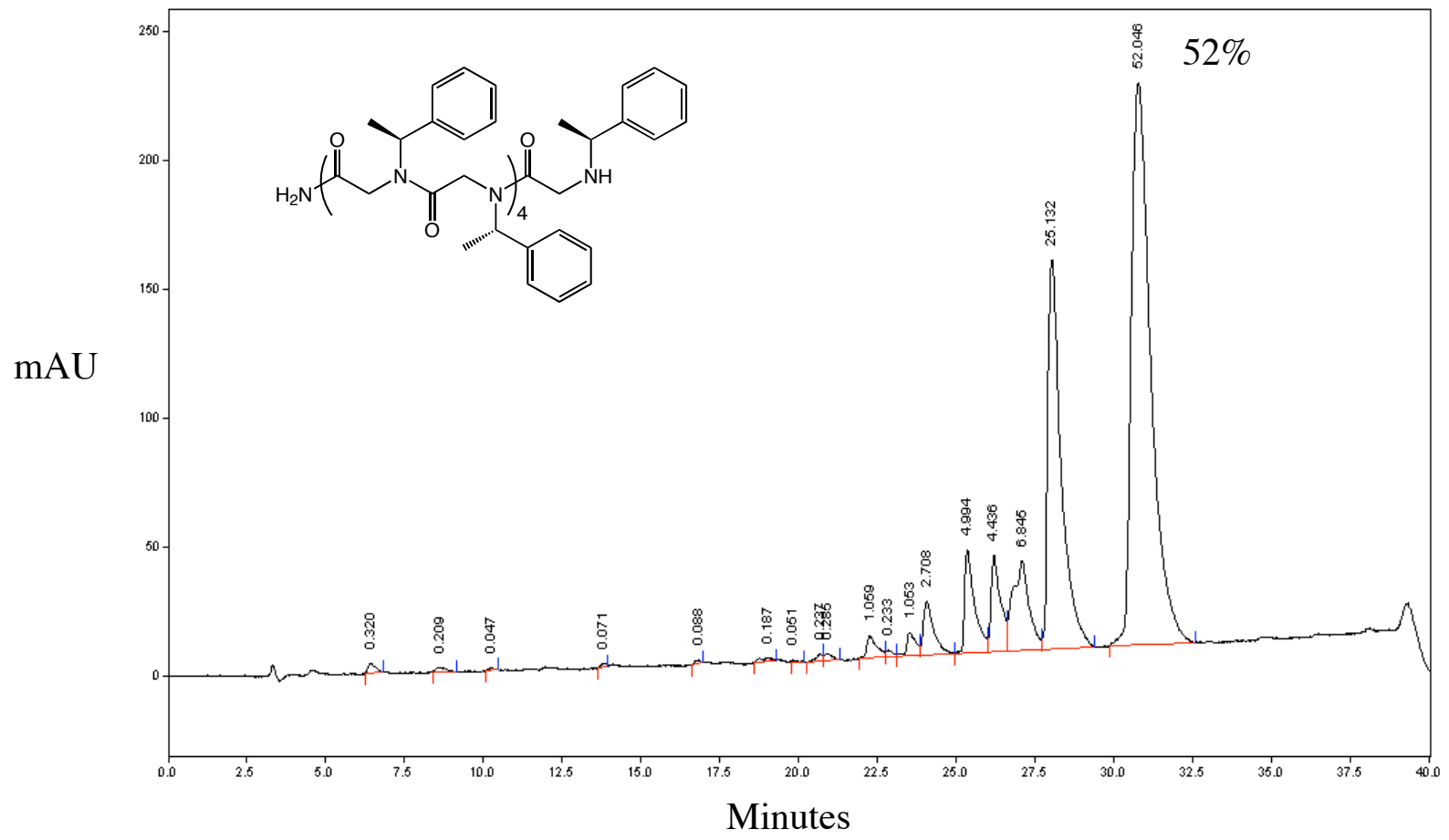




\section{Mass Spectrometry Data}

Table S-1. MS data for peptoid homo-pentamers.

\begin{tabular}{llll}
\hline Amine & Peptoid & Calculated Mass & Observed Mass \\
\hline $\mathbf{5}$ & $(N \mathrm{spe})_{5}$ & 822.5 & $823.2\left[\mathrm{M}+\mathrm{H}^{+}\right]^{+}$ \\
$\mathbf{6}$ & $(N \mathrm{sch})_{5}$ & 852.7 & $853.8\left[\mathrm{M}+\mathrm{H}^{+}\right]^{+}$ \\
$\mathbf{7}$ & $(N \mathrm{pm})_{5}$ & 752.4 & $753.1\left[\mathrm{M}+\mathrm{H}^{+}\right]^{+}$ \\
$\mathbf{8}$ & $(N \mathrm{spp})_{5}$ & 892.5 & $893.3\left[\mathrm{M}+\mathrm{H}^{+}\right]^{+}$ \\
$\mathbf{9}$ & $(N \mathrm{fpe})_{5}$ & 1272.2 & $1272.9\left[\mathrm{M}+\mathrm{H}^{+}\right]^{+}$ \\
$\mathbf{1 0}$ & $(N 2 \mathrm{fb})_{5}$ & 842.3 & $843.2\left[\mathrm{M}+\mathrm{H}^{+}\right]^{+}$ \\
$\mathbf{1 1}$ & $(N 3 \mathrm{fb})_{5}$ & 842.3 & $843.1\left[\mathrm{M}+\mathrm{H}^{+}\right]^{+}$ \\
$\mathbf{1 2}$ & $(N 4 \mathrm{fb})_{5}$ & 842.3 & $843.1\left[\mathrm{M}+\mathrm{H}^{+}\right]^{+}$ \\
$\mathbf{1 3}$ & $(N 2,6 \mathrm{fb})_{5}$ & 932.3 & $933.0\left[\mathrm{M}+\mathrm{H}^{+}\right]^{+}$ \\
$\mathbf{1 4}$ & $(N 3,5 \mathrm{fb})_{5}$ & 932.3 & $932.9\left[\mathrm{M}+\mathrm{H}^{+}\right]^{+}$ \\
$\mathbf{1 5}$ & $(N 2 \mathrm{nb})_{5}$ & 977.3 & $1000.0\left[\mathrm{M}+\mathrm{Na}^{+}\right]^{+}$ \\
$\mathbf{1 6}$ & $(N 3 \mathrm{nb})_{5}$ & 977.3 & $978.3\left[\mathrm{M}+\mathrm{H}^{+}\right]^{+}$ \\
$\mathbf{1 7}$ & $(N 4 \mathrm{nb})_{5}$ & 977.3 & $978.2\left[\mathrm{M}+\mathrm{H}^{+}\right]^{+}$ \\
$\mathbf{1 8}$ & $(N 2 \mathrm{mb})_{5}$ & 822.5 & $823.2\left[\mathrm{M}+\mathrm{H}^{+}\right]^{+}$ \\
$\mathbf{1 9}$ & $(N 4 \mathrm{mob})_{5}$ & 902.4 & $903.1\left[\mathrm{M}+\mathrm{H}^{+}\right]^{+}$ \\
& $(N a n i l i n e)_{5}$ & 682.3 & $683.0\left[\mathrm{M}+\mathrm{H}^{+}\right]^{+}$ \\
\hline
\end{tabular}

Table S-2. MS data for peptoid nonamers (20-22).

\begin{tabular}{lcll}
\hline Peptoid & Amines & Calculated Mass & Observed Mass \\
\hline 20: $[(N \text { spe })(N 2 \mathrm{fb})]_{4}(N \mathrm{spe})$ & $\mathbf{5 , 1 5}$ & 1590.7 & $1591.2\left[\mathrm{M+ \textrm {H } ^ { + } ] ^ { + }}\right.$ \\
21: $[(N \mathrm{spe})(N \mathrm{spe})(N 2 \mathrm{fb})]_{3}$ & $\mathbf{5 , 1 5}$ & 1559.7 & $1561.2\left[\mathrm{M}+\mathrm{H}^{+}\right]^{+}$ \\
22: $(N \mathrm{spe})_{9}$ & $\mathbf{5}$ & 1466.8 & $1489.8\left[\mathrm{M}+\mathrm{Na}^{+}\right]^{+}$ \\
\hline
\end{tabular}

